\title{
The Effects of Neutral Inertia on Ionospheric Currents in the High-Latitude Thermosphere Following a Geomagnetic Storm
}

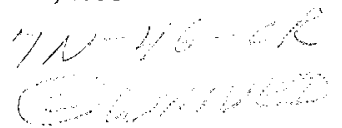

\author{
W. DENG, T. L. KILLEEN, AND A. G. BURNS \\ Space Physics Research Laboratory, Department of Atmospheric, Oceanic and Space Sciences, \\ The University of Michigan, Ann Arbor \\ R. G. ROBLE
}

High Altitude Observatory, National Center for Atmospheric Research, Boulder, Colorado

J. A. SLAVIN AND L. E. WhaRTON

NASA Goddard Space Flight Center, Greenbelt, Maryland

\begin{abstract}
Results of an experimental and theoretical investigation into the effects of the time dependent neutral wind flywheel on high-latitude ionospheric electrodynamics are presented. The results extend our previous work [Deng et al., 1991] which used the National Center for Atmospheric Research Thermosphere/lonosphere General Circulation Model (NCAR TIGCM) to theoretically simulate flywheel effects in the aftermath of a geomagnetic storm. The previous results indicated that the neutral circulation, set up by ion-neutral momentum coupling in the main phase of a geomagnetic storm, is maintained for several hours after the main phase has ended and may dominate height-integrated Hall currents and field-aligned currents for up to 4-5 hours. We extend the work of Deng et al. to include comparisons between the calculated time-dependent ionospheric Hall current system in the storm-time recovery period and that measured by instruments on board the Dynamics Explorer 2 (DE 2) satellite. Also, comparisons are made between calculated field-aligned currents and those derived from DE 2 magnetometer measurements. These calculations also allow us to calculate the power transfer rate (sometimes called the Poynting flux) between the magnetosphere and ionosphere. The following conclusions have been drawn: (1) Neutral winds can contribute significantly to the horizontal ionospheric current system in the period immediately following the main phase of a geomagnetic storm, especially over the magnetic polar cap and in regions of ion drift shear. (2) Neutral winds drive Hall currents that flow in the opposite direction to those driven by ion drifts. (3) The overall morphology of the calculated field-aligned current system agrees with previously published observations for the interplanetary magnetic field (IMF) $\mathrm{B}_{\mathrm{Z}}$ sonthward conditions, although the region 1 and region 2 currents are smeared by the TIGCM model grid resolution. (4) Neutral winds can make significant contributions to the field-aligned current system when $\mathrm{B}_{\mathrm{Z}}$ northward conditions prevail following the main phase of a storm, but can account for only a fraction of the observed currents. (5) DE 2 measurements provide a demonstration of "local" (satellite-altitude) flywheel effects. (6) On the assumption that the magnetosphere acts as an insulator, we calculate neutral-wind-induced polarization electric fields of $\sim 20-30 \mathrm{kV}$ in the period immediately following the geomagnetic storm.
\end{abstract}

\section{INTRODUCTTON}

The electrodynamic effects of thermospheric winds have been studied by many authors [Richmond and Roble, 1987; Blanc and Richmond, 1980; Forbes and Harel, 1989; Forbes and Lindzen, $1976 a, b, 1977]$. Their studies show that ionospheric currents in the low and middle latitudes are driven mainly by the polarization electric fields generated by the neutral wind dynamo, although the magnetosphere may have some influence on these currents through disturbance dynamo processes. On the other hand, electric currents at high latitudes are driven primarily by convection electric fields that originate in the magnetosphere. These electric fields, in turn, also affect the high-latitude, neutral circulation in the thermosphere through the ion drag mechanism. The magnetospheric convection electric field maps into the high-latitude ionosphere and causes the ions to drift in an ExB direction at $\mathrm{F}$ region altitudes, typically resulting in a twin-celled ionospheric convection pattern [Heppner, 1977; Heelis et al., 1982; Sojka and Schunk,

\section{Copyright 1993 by the American Geophysical Union.}

Paper number 92JA02268.

0148-0227/93/92JA-02268\$05.00
1986] for southward interplanetary magnetic field conditions (IMF $\mathrm{B}_{\mathrm{Z}}$ southward). The convecting ions also impart momentum to the neutral gas through ion drag forcing, which causes the neutral winds to adopt a circulation pattern which is, in many respects, similar to the ion convection pattern. Various authors [e.g., Killeen et al., 1982, 1984b 1986; Roble et al., 1984; Hays et al., 1979, 1984] have shown that this ion drag not only affects neutral winds strongly in the $F$ region, but also has a significant effect on neutral winds in the conducting $E$ region.

The National Center for Atmospheric Research thermospheric general circulation model (NCAR TGCM) was used to study the momentum forcing terms of the neutral winds in the lower thermosphere by Killeen and Roble [1984]. They found that high-latitude $E$ region neutral winds can be driven to follow the ion convection pattern by ion drag forcing, with the peak speed of the neutrals being roughly one fourth that of the ions during summer. While a sustained pattern of ionospheric convection drives a neutral circulation pattern with broadly similar characteristics, a sudden change in ion convection may result in large transient ion-neutral difference velocities. These large velocity differences may last for several hours, a result of the relatively long time constant in the $\mathrm{E}$ region for the transfer of momentum from the plasma to the neutral gas [Killeen et al., 
1984a; Ponthieu et al., 1988]. Thus, neutral winds that are forced by ions during a geomagnetic storm can persist for a long time into the recovery phase, and may drive significant ionospheric and magnetospheric currents over the polar cap by processes similar to that of the dynamo in low and middle latitudes.

Lyons et al. [1985] studied the "left over" winds and showed that the neutral circulation in the high-latitude $E$ region can drive a significant Hall current system for up to six hours after the cessation of strong magnetospheric convection, the socalled neutral "flywheel" effect. Recently we reevaluated the work of Lyons et al. [1985] using a far more realistic NCAR thermosphere/ionosphere general circulation model (TIGCM) simulation, rather than the simplified case used previously [Deng et al., 1991]. In this version of the TIGCM the ionosphere is calculated self-consistently so that more accurate estimations of the effects of the neutral circulation on ionospheric currents can be made. Thus, we were able to make better quantitative estimates of the changes in Hall currents, both during a geomagnetic storm and during its immediate aftermath. Among other results, we found that, in some highlatitude regions, neutral-wind-driven currents could account for as much as $80 \%$ of the total Hall current system in the period immediately following a major storm, and that neutral winds could continue to dominate high-latitude Hall currents for 4 to 5 hours after the end of the main phase. Additionally, we were able to estimate the field-aligned currents by utilizing the vector spherical harmonic (VSH) analysis representation of the thermosphere [Killeen et al., 1987] and by assuming that the magnetosphere was a perfect conductor. The modeled fieldaligned currents were in good agreement with values obtained from experimental studies [e.g., Iijima and Potemra, 1978] during the southward $\mathrm{B}_{\mathrm{Z}}$ conditions that prevailed during the main phase of the storm, but, while showing morphological agreement, their magnitudes were too small in the period immediately after the main phase.

The neutral wind dynamo may generate both currents and polarization electric fields in the high-latitude ionosphere. To calculate these currents and electric fields rigorously requires knowledge of specific magnetospheric boundary conditions for the high-latitude thermosphere/ionosphere dynamo and detailed information about the magnetospheric "load." This load may be modeled in terms of a perfectly conducting magnetosphere, with infinite conductivities, or in terms of a perfectly insulating magnetosphere, with zero conductivities. The "real" magnetosphere probably lies somewhere between these two extremes. A good analogy for this system can be found by considering it as an electric circuit, in which the magnetospheric generator is a battery with an internal resistance that represents the magnetospheric load. If the magnetospheric conductivities are very large compared with ionospheric conductivities, the neutral dynamo can be considered as a pure current generator when it is connected to the magnetosphere. Any divergence in the ionospheric horizontal currents must be balanced by field-aligned currents to prevent the ionospheric electric fields from being modified significantly by the neutral dynamo. Alternatively, the magnetosphere can be considered as an insulator, in which case there are no field-aligned currents and the neutral dynamo acts as a pure voltage generator. Thus, polarization electric fields are created in the high-latitude ionosphere. Again, it must be stated that the real situation in the magnetosphere-ionosphere system is probably some combination of these two extremes.
In this paper, we extend our previous work on storm-enhanced neutral dynamo effects, and present comparisons between numerical model calculations and observational data from the Dynamics Explorer 2 (DE 2) mission. The NCAR TIGCM is used to simulate a geomagnetic storm that occurred on November 23, 1982. Using this simulation, the time-dependent Hall currents, field-aligned currents, and electrical power (Poynting) fluxes between the magnetosphere and the ionosphere are calculated, both during the main phase of the storm and in the period immediately following this main phase. We discuss the new results in terms of the two extreme magnetospheric load assumptions mentioned above. Finally, we also present a comparison between TIGCM predictions and DE 2 satellite measurements, made for another, smaller geomagnetic storm, which provides direct observational evidence for the existence of the flywheel effect at the altitude of satellite orbit.

\section{NCAR TIGCM}

The NCAR TGCM is a three-dimensional, time-dependent model of the Earth's neutral upper atmosphere that is run on the CRAY-YMP computer at NCAR. The model uses a finitedifferencing technique to obtain time-dependent solutions of the coupled, nonlinear equations of momentum, thermodynamics, and mass continuity for the neutral thermosphere [Dickinson et al., 1981, 1984; Roble et al., 1982]. Recently, the TGCM has been upgraded to include an interactive ionosphere within the same model formulation [Roble et al., 1988]. The new NCAR TIGCM solves the ion energy and ion continuity equations selfconsistently with the equivalent equations for the neutral constituents, thus enabling us to perform a preliminary study of some feedback processes described above. The TIGCM has a $5^{\circ}$ latitude-by-longitude grid with 24 constant pressure surfaces in the vertical, extending from approximately 97 to $500 \mathrm{~km}$ in altitude. The ion convection pattern used within the TIGCM is based on the Heelis et al. [1982] model. The parameterization of this ion convection pattern is tied to estimates of the total auroral hemispherical power input from the NOAA/TIROS particle flux measurements and may be varied in a timedependent fashion to simulate variations in the solar wind/magnetospheric dynamo. In this paper we utilize the model results, together with the diagnostic processor developed by Killeen and Roble [1984] and the Vector Spherical Harmonic (VSH) representation of the output fields of the TIGCM [Killeen et al., 1987], to study the effects of neutral inertia on ionospheric currents.

Burns et al. [1992] have discussed a time-dependent TIGCM simulation approptiate for the geophysical conditions that existed on the 5 days up to and including the large geomagnetic storm that occurred on November, 23 1982. The magnetospheric inputs during this period were specified using algorithms developed by P. Reiff and B. Emery [Reiff et al., 1985; Reiff and Luhmann, 1986; B. A. Emery, private. communication, 1987]. The results of this simulation have been shown to be in good agreement with DE 2 satellite measurements of neutral composition during the storm mentioned above, implying that most of the important physical processes controlling the energetics and dynamics of thermosphere are reasonably well represented in the model. We use the output of this simulation to calculate height-integrated ionospheric currents, field-aligned currents and a polarization electric field using the Killeen and Roble [1984] diagnostic package.

This geomagnetic storm commenced at about 1500 hours 
universal time (UT) on day 327 (November 23) 1982. The IMF $\mathrm{B}_{\mathrm{Z}}$ component turned southward after $1500 \mathrm{UT}$ and continued to have large negative values for several hours. $K p$ reached values of $6^{+}$during this storm, and relatively strong geomagnetic activity continued for $\sim 7$ hours after commencement. The elevated levels of geomagnetic activity and the high IMF values imply that large cross-cap potential drops occurred during the storm. Figure 1 shows the IMF parameters and cross-cap potential used in the model simulation. At 2300 UT geomagnetic activity dropped suddenly as $B_{Z}$ turned northward and the magnitude of $B_{y}$ decreased. It is difficult to estimate accurately the cross-cap potential when $B_{Z}$ is northward due to the complexity of the ion-convection pattern and the limitations of the existing parameterizations of this pattern. However, $B_{Z}$ northward conditions are associated with less coherent and generally much weaker ion drifts than those typically observed for $\mathrm{B}_{Z}$ negative conditions. For the purposes of this study, therefore, we assume a constant cross-cap potential of $11 \mathrm{kV}$ for the $\mathrm{B}_{\mathrm{Z}}$ northward period to represent the much reduced level of ion drag forcing.

\section{The Hall Current System}

Deng et al. [1991] described the results of a study of the effects of neutral inertia on the Hall and field-aligned current systems that was done using a simulation of the November 23 , 1982 storm. Several aspects of this work could not be included in the aforementioned paper because of length considerations; thus, additional material is presented here when appropriate. However, we only repeat the discussion included in the work of

Cross-cap Potential
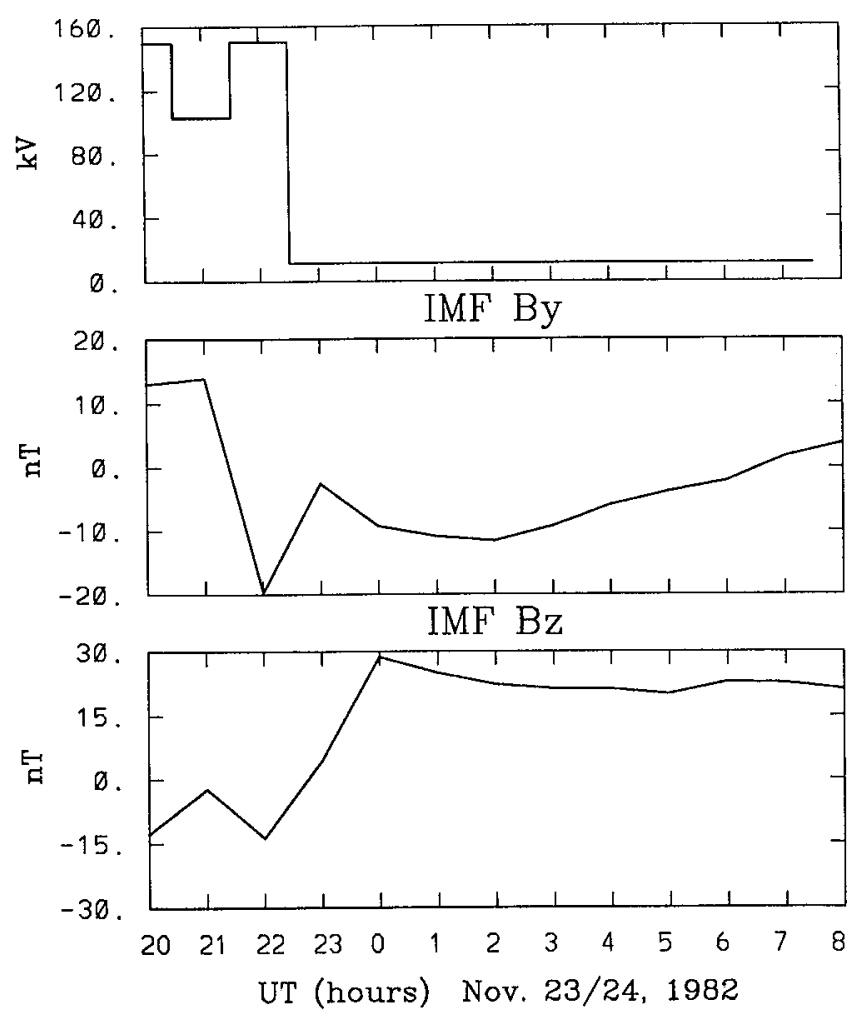

Fig. 1. Calculated cross-cap potential (Top) and measured IMF parameters during the storm that occurred on November 23, 1982. The IMF values were made available by the National Space Science Data Center. (Middle) the IMF $\mathrm{B}_{\mathrm{y}}$ component. (Bottom) the $\mathrm{B}_{\mathrm{z}}$ component.
Deng et al. [1991] when it is relevant to the results of our comparisons with DE 2 data.

The relative importance of neutral winds on the ionospheric currents can be assessed by looking the neutral and ion contributions to the Hall current system separately. The diagnostic package of Killeen and Roble [1984] was applied to output from the NCAR TIGCM to calculate both ionospheric conductivities and this current system. The Appendix contains the relevant equations used. Figure 2 shows the calculated height-integrated Hall conductivities at $2200 \mathrm{UT}$, just before the end of the main phase of the storm, and at 2300 UT, just after the end of the main phase of the storm. Increased electron precipitation during the main phase of the storm enhances the conductivities in the auroral zone (see Figure $2 a$ ). There is no evidence of auroral enhancement in the height-integrated conductivities at $2300 \mathrm{UT}$, after the main phase of the storm has ended (Figure 2b). The November 23, 1982 storm was very suitable for our study of flywheel effects because of the very sharp cutoff in auroral forcing, which is exemplified by the dominance of the high-latitude conductivities by solar effects at 2300 UT.

Calculations of height-integrated Hall currents were presented by Deng et al. [1991]. In that paper and in the current work we assume that the magnetosphere acts as a perfect conductor with respect to the neutral dynamo, therefore no polarization electric field is set up. We repeat their results here to indicate the changes that may occur when neutral inertia influences ionospheric currents in the period after the main phase of the storm. Thus, the later comparisons between model results and satellite data will be better understood. Figure 3 shows individual components of the calculated height-integrated Hall current system just before the end of the storm, at 2200 UT. Figures $3 a$ and $3 b$ depict the portions of the Hall current system driven by the neutral winds and by the ion winds, respectively (see Appendix). The "neutral" Hall current component, shown in Figure $3 a$, has approximately the same characteristic pattern as the neutral winds themselves in the $E$ region except in the auroral region where the corresponding magnitudes of the currents are larger, a result of enhanced auroral conductivities. Since the Hall conductivities maximize in the lower thermosphere, the neutral component of the Hall current is dominated by the neutral winds in the lower thermosphere, and is not strongly influenced by neutral winds higher up. However, the "ion" component of the Hall current behaves very differently from the neutral component. The ion Hall current pattern shown in the Figure $3 b$ has a very similar pattern to that of the ion drifts in the $F$ region except, of course, for the fact that the ion winds move in the opposite direction to the Hall currents (see equation (A3)). The combination of these ion and neutral components results in a Hall current system that is dominated by the ion component during the main phase of the geomagnetic storm, as is shown in Figure $3 c$. The magnitudes of these ion-driven Hall currents are reduced somewhat by the neutral component, which acts in the opposite direction to the ion component. Figure $3 d$ illustrates the percentage contribution of the neutrals to the total Hall current system. The neutral contribution never exceeds $40 \%$ anywhere at latitudes higher than $40^{\circ}$, and is much smaller than that through most of the high-latitude region. The areas where the neutral component is most important $(30-40 \%)$ are found at subauroral latitudes near local noon and midnight regions where the ion winds are weak, but where the neutral winds remain strong.

At around $2300 \mathrm{UT}, \mathrm{B}_{\mathrm{Z}}$ turned northward, so the parameterized 


\section{Hall Conductivity}

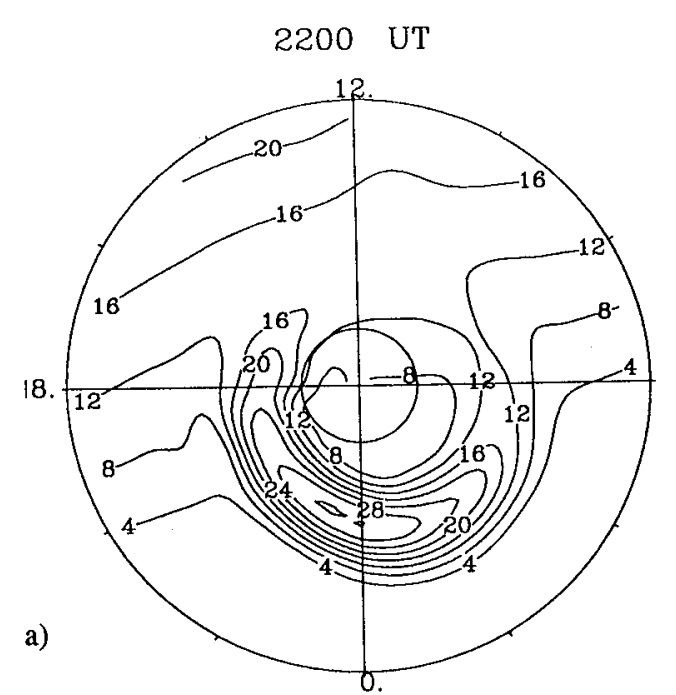

contour by 1.0 mho

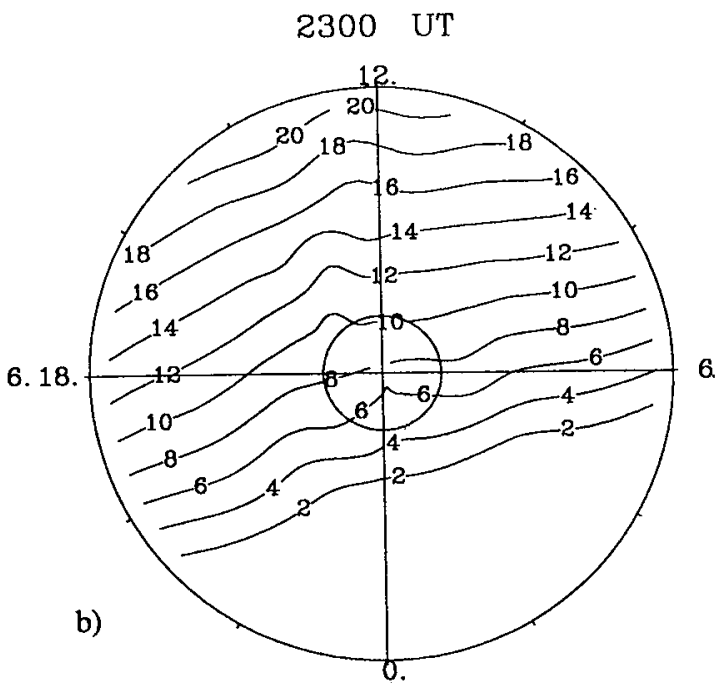

contour by 1.0 mho

\section{Pedersen Conductivity}

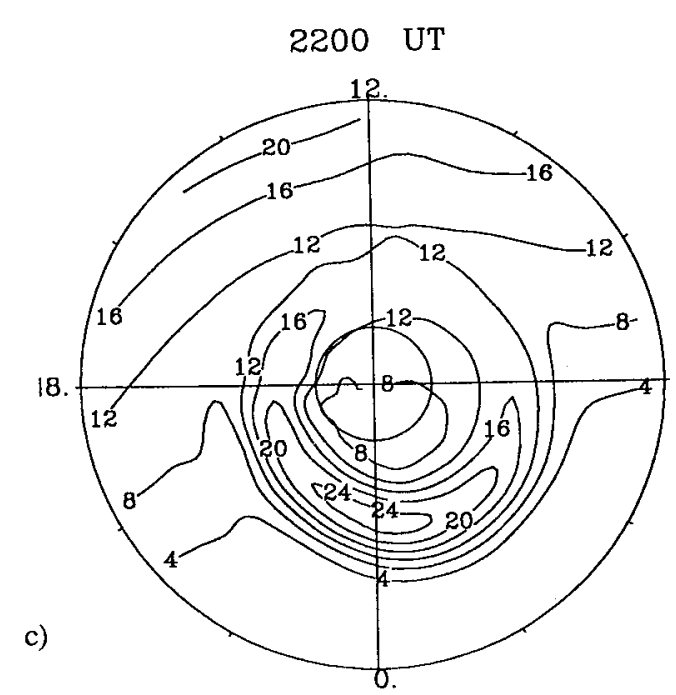

contour by 1.0 mho

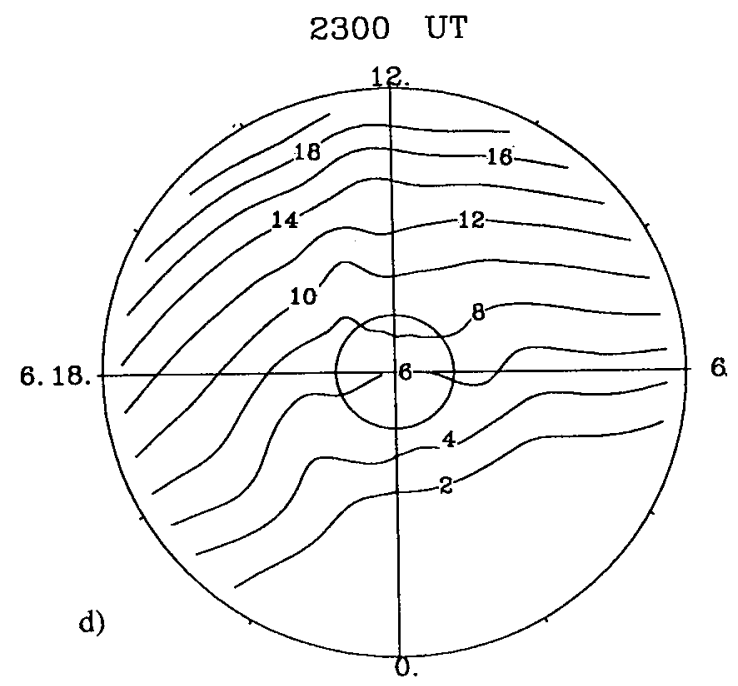

contour by 1.0 mho

\section{South Pole Geomagnetic Coords}

Fig. 2. Calculated height-integrated Hall and Pedersen conductivities at 2200 UT and at 2300 UT in the southern hemisphere using geomagnetic coordinates from $40^{\circ} \mathrm{S}$ to the geomagnetic pole.

cross-cap potential was made to drop from about $150 \mathrm{kV}$ to 11 $\mathrm{kV}$ (see Figure 1). As a result of this cross-cap potential drop, the maximum magnitude of the ion drifts decreased from about $2000 \mathrm{~m} / \mathrm{s}$ to about $150 \mathrm{~m} / \mathrm{s}$, which, in turn, leads to a significant reduction in the ion component of the Hall current system. However, neutral winds in the lower thermosphere do not change so rapidly, because of the large inertia of the neutral gas. These neutral winds can drive a significant portion of the Hall current system after ion forcing is diminished at the end of the substorm, and the neutral component of the Hall current becomes larger than the ion component at this time (the "flywheel" effect). This neutral component of the Hall current, which dominates at $2300 \mathrm{UT}$, is directed in the opposite direction to the magnetospheric-convection-driven, polar cap current system that dominates during southward $\mathrm{B}_{\mathbf{Z}}$ conditions. Neutral-driven Hall currents also have double-vortex forms, but the current flows in an antisunward direction over the polar cap and in a sunward direction at lower latitudes.

Figure 4 shows the neutral component, the ion component and the total Hall current at 2300 UT, during the recovery phase of the storm. Figure 4 uses the same format as Figure 3. It is immediately apparent that the modeled total Hall current system (Figure $4 c$ ) is dominated by the neutral component (Figure $4 a$ ). Figure $4 d$ shows the contribution of the neutral component to the total current. At this time the neutral component can account for up to $80 \%$ of the total current in the premidnight sector 


\section{Hall Currents: 2200 UT}
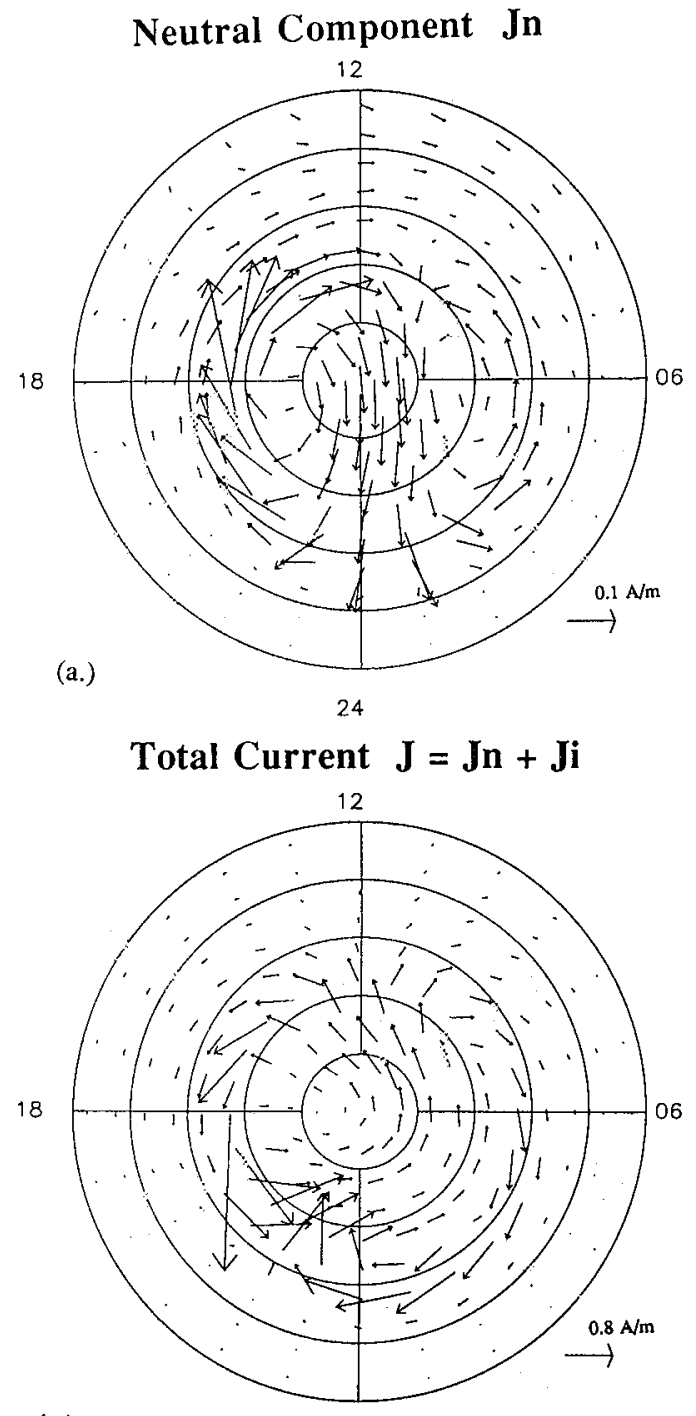

(c.)

24
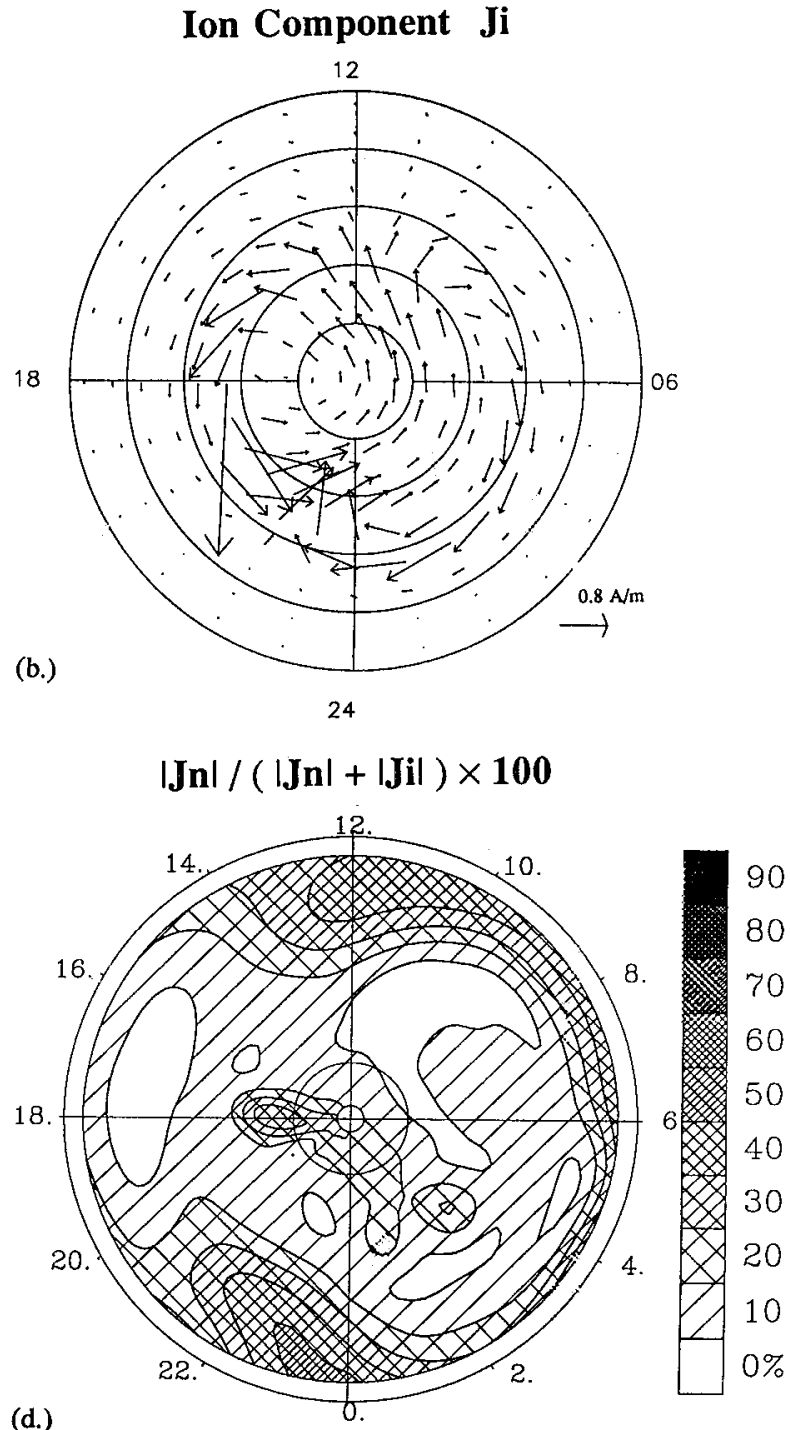

(d.)

\section{South Pole Geomagnetic Coords}

Fig. 3. Calculated height-integrated Hall currents in the sonthern hemisphere for $(a)$ the neutral component, $(b)$ the ion component and $(c)$ the total current. $(d)$ The contribution of the neutral component to the total current, calculated using $\left|\mathbf{J}_{\mathbf{n}}\right| /\left(\left|\mathbf{J}_{\mathbf{n}}\right|+\left|\mathbf{J}_{\mathbf{i}}\right|\right) \times 100$, is given as a percentage. These values are plotted in the geomagnetic coordinates from $40^{\circ} \mathrm{S}$ to the geomagnetic pole at $2200 \mathrm{UT}$.

between $40^{\circ}$ and $70^{\circ} \mathrm{S}$ geomagnetic latitudes. At latitudes polarward of $70^{\circ} \mathrm{S}$, the neutral contribution is somewhat less, due to the relatively strong ion component of the Hall current, an indication that the ion convection pattern is still important at these latitudes in our simulation. Overall, the average contribution of the neutral winds to the Hall current at magnetic latitudes polarward of $60^{\circ} \mathrm{S}$ is $\sim 65 \%$.

Antisunward Hall currents and their associated electric fields have been observed during northward $\mathrm{B}_{\mathbf{z}}$ conditions by many authors [Maezawa, 1976; Burke et al., 1979; Reiff, 1982; Zanetti et al., 1984]. Normally, the currents that occur in these conditions have been associated with sunward plasma convection flow. Our calculations, which do not include possible sunward, magnetospheric-driven, ion convective flow, indicate quantitatively that neutral flywheel effects can also make a significant contribution to these sunward Hall currents.

\section{The Field-Aligned CURRENT System and the POLARIZATION ELECTRIC FIELIS}

Two possible extremes exist when connections between the ionosphere and the magnetosphere are considered. In the first case, the magnetosphere can be considered as a perfect conductor and the field-aligned currents can be approximated by taking the divergence of the Pedersen currents. The second extreme involves treating the magnetosphere as a perfect insulator. In this case field-aligned currents do not occur, and any existing Pedersen currents will set up a polarization electric field. The real situation probably lies somewhere between these two extremes, but it is worthwhile to examine each of them to gain a better understanding of the physical processes occurring during the immediate post storm period.

When the sign of the $\mathrm{z}$ component of the interplanetary 


\section{Hall Currents: 2300 UT}
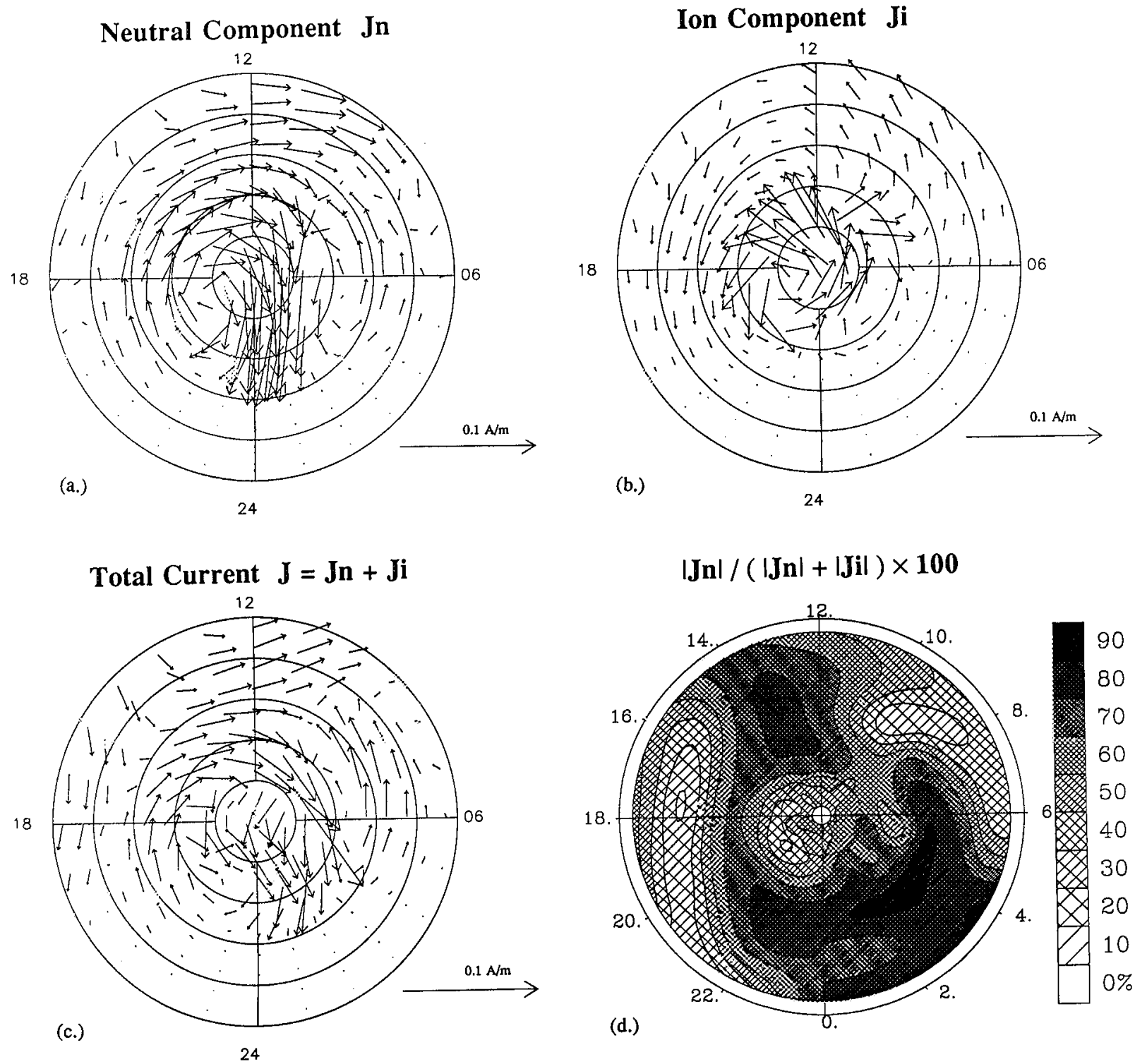

\section{South Pole Geomagnetic Coords}

Fig. 4. The same as Figure 3 except at 2300 UT.

magnetic field is negative (southward $B_{Z}$ conditions) fieldaligned currents occur in a two-region pattern that has been described by Iijima and Potemra [1978] and others. Therefore, we were able to test the realism of our modeled field-aligned current system by seeing if we could reproduce this two-region current pattern during $\mathrm{B}_{\mathrm{z}}$ southward conditions. The fieldaligned currents, $J_{\|}$, are calculated by applying equations (A4) to (A6) in the appendix to the output field of the NCAR TIGCM within the framework of the VSH algorithm discussed by Killeen et al. [1987]. Our modeled values for the southern (summer) hemisphere, field-aligned currents are given in Figure 5a. The polar dial extends from the geomagnetic south pole to $40^{\circ} \mathrm{S}$ and the results are for $2200 \mathrm{UT}$, during the main phase of the geomagnetic storm.

These calculated field-aligned currents reproduce the two- region morphology described by lijima and Potemra [1978]. Downward region 1 currents are found at latitudes between $65^{\circ} \mathrm{S}$ and $75^{\circ} \mathrm{S}$ in the morning sector, while they are directed upward in the evening sector at similar latitudes. Region 2 currents occur at lower latitudes and flow in the opposite direction to the region 1 currents. The maximum region 1 current densities in Figure $5 a$ are of the same order of magnitude as those of Iijima and Potemra [1978]. The maximum values of about $1.5 \mu \mathrm{A} / \mathrm{m}^{2}$ and $1.9 \mu \mathrm{A} / \mathrm{m}^{2}$ occur at 1900 local magnetic time in the evening sector and 0200 local magnetic time in the morning sector respectively.

Several potential sources of error exist in our calculations. First, our field-aligned currents are calculated using output from the NCAR-TIGCM, which has a resolution of $5^{\circ}$ in latitude and longitude. This relatively coarse resolution spreads the field- 


\section{FIELD-ALIGNED CURRENTS}

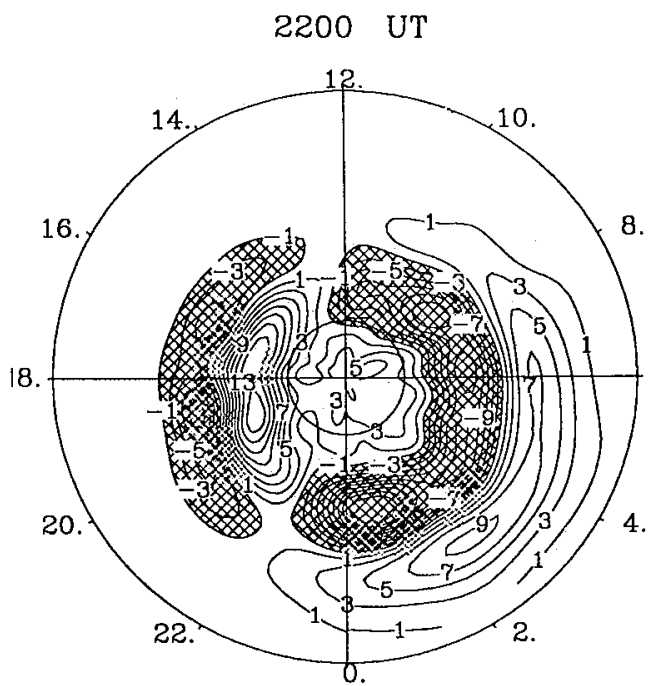

a) contour by $0.1 \mu \mathrm{A} / \mathrm{m}^{2}$

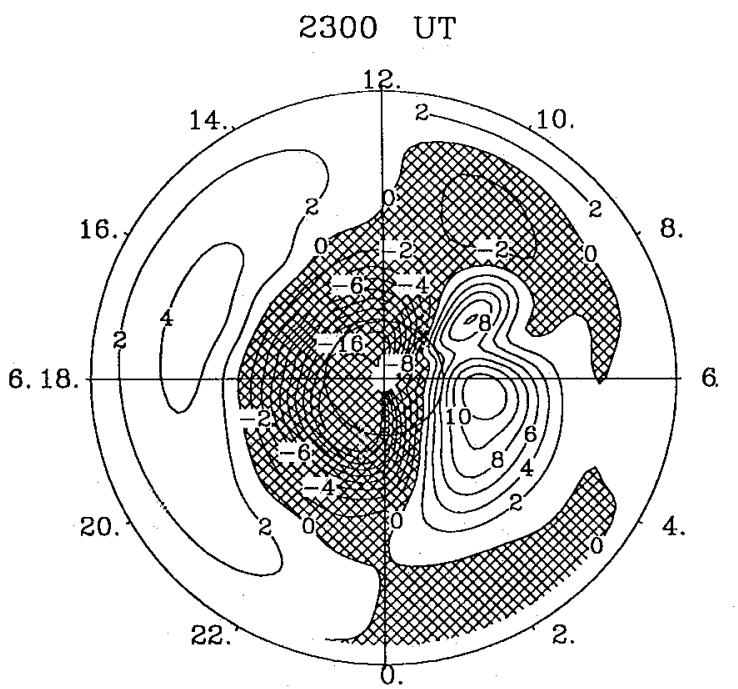

b) contour by $0.01 \mu \mathrm{A} / \mathrm{m}^{2}$

\section{current into ionosphere \\ current away from ionosphere \\ South Pole Geomagnetic Coords}

Fig. 5. Calculated field-aligned current density over the southern hemisphere using geomagnetic coordinates from $40^{\circ} \mathrm{S}$ to the geomagnetic pole at $(a) 2200$ UT and (b) 2300 UT. Zero magnetospheric load is assumed.

aligned currents out over a latitude range that is wider than the observed width of the individual field-aligned current regions. This smearing not only increases the latitudinal extent of the two regions, but also decreases the magnitudes of the fieldaligned currents. Second, some additional smearing occurs when the VSH algorithm is applied to the output fields of the NCAR TIGCM. Third, an accurate prescription of the auroral oval within the NCAR TIGCM is difficult. Various parameterizations of particle precipitation and the ion convection pattern are used in the NCAR TIGCM and, while these give a good general picture of magnetospheric inputs during $\mathrm{B}_{\mathrm{Z}}$ southward conditions, they may not be appropriate for a particular geomagnetic storm. In addition, when we simulated the storms used in this paper we used generalized magnetospheric inputs rather than the more accurate assimilative mapping of ionospheric electrodynamic (AMIE) technique [e.g., Richmond and Kamide, 1988]. Later in this paper we make direct comparisons between our calculations of field-aligned currents and those calculated from DE 2 data. These sources of error are apparent in these comparisons, so they will be discussed further there.

After the end of the main phase of the storm, the field-aligned current pattern has a very different morphology. In our simulation of this storm we cut off geomagnetic forcing almost completely after 2200 UT, leaving only a very small magnetospheric contribution to the ionospheric current system. Thus, neutral winds dominate the modeled field-aligned current system in another manifestation of the flywheel effect. The resultant structure of these field-aligned currents at $2300 \mathrm{UT}$ is shown in Figure $5 b$. By this time their morphology has changed considerably from their normal two-region current pattern. A large region of downward currents is seen in the evening sector at latitudes above $65^{\circ} \mathrm{S}$. There are two large regions of upward currents. One is in the evening sector with a peak at about $60^{\circ} \mathrm{S}$. The other is in the morning sector with a peak at about $75^{\circ} \mathrm{S}$. The average densities of these currents polarward of $75^{\circ} \mathrm{S}$ are $0.13 \mu \mathrm{A} / \mathrm{m}^{2}$ for downward (eveningside) currents and 0.08 $\mu \mathrm{A} / \mathrm{m}^{2}$ for upward (morningside) currents.

Such large-scale, field-aligned current distributions have been observed in the dayside by Iijima et al. [1984] for $\mathrm{B}_{\mathrm{Z}}>5 \mathrm{nT}$. However, their reported current densities are 3 times greater than the densities of the downward (eveningside) currents that we calculated, and about an order of magnitude greater than those of the upward (morningside) currents. Zanetii et al. [1984] have used the same observational data as Iijima et al. [1984] to determine the morphology of the Hall currents in the polar cap, and they confirmed the presence of antisunward flowing Hall currents during northward IMF, which is consistent with our predictions of their behavior, made in the previous section. In summary, although there is a discrepancy between the experimental results and our calculations of the magnitude of the "neutral-driven" field-aligned current system during storm time recovery, there is general agreement as to the morphology of the field-aligned current system.

In the preceding paragraphs the magnetosphere was treated as a perfect conductor, however there is the opposite extreme in which the magnetosphere may be considered to act as an insulator. Under this condition no field-aligned currents would flow, and the high-latitude, neutral dynamo would tend to set up a polarization electric field, and thus act purely as a voltage generator. To assess the magnitude of this polarization electric field, the dynamo equation must be solved in the high-latitude 
ionosphere, and the potential $\phi$ is defined by [Forbes and Harel, 1989]

$$
\nabla \cdot[\Sigma \cdot(-\nabla \phi)]=\mathrm{j}_{\|}-\nabla \cdot \int \sigma \bullet(\mathbf{U} \times \mathbf{B}) \mathrm{dz}
$$

where $\mathbf{U}$ is the neutral wind, $\mathbf{B}$ is the magnetic field vector, $\sigma$ is the conductivity tensor, $\Sigma$ is the height-integrated conductivity tensor and $\mathrm{z}$ is the altitude. This equation is solved in geomagnetic coordinates for the region from $40^{\circ} \mathrm{S}$ to the south geomagnetic pole. In order to avoid a singularity at the pole, we use a mixed finite difference and spectral approach in which the divergence of the neutral wind term is calculated first by using VSH techniques, and is then solved near the pole using a finite difference algorithm. The boundary condition for the potential at $40^{\circ} \mathrm{S}$ is set arbitrarily to be zero. Figure 6 shows the potential distribution in the southern hemisphere for 2300 UT, just after the end of the storm. At this time a two-cell potential pattern exists. The evening cell has a minimum value of $-27 \mathrm{kV}$, while the morning cell has a peak value of $14 \mathrm{kV}$. The magnitude of the evening cell is greater than that of the morning cell due to the stronger neutral winds that exist in the evening sector [e.g., Killeen et al., 1986]. This potential pattern is quite similar to the convection pattern driven by magnetospheric electric fields during southward $\mathrm{B}_{\mathrm{Z}}$ conditions, because the dynamo effect of the neutral winds maintains the convection that existed during the storm, albeit with decreasing amplitude as time goes by. A major source of uncertainty in this calculation is the boundary conditions used at $40^{\circ} \mathrm{S}$, which cuts off all coupling processes with lower latitudes. In reality, the low-latitude dynamo will influence the high-latitude electrodynamics, and so it should be taken into account.

\section{POWER FluX}

Up to this time we have discussed the flywheel effect in terms of the height-integrated Hall currents and the field-aligned currents. Another way to look at the problem is to study the vertical power flux (sometimes called the Poynting flux). Dynamic coupling between the magnetosphere and the thermosphere results in complex feedback processes of energy exchange between the solar wind/magnetospheric dynamo and the thermospheric dynamo. The net power flux between the two generators and their loads provides a measure of the electrical energy flow. In general, this net power flux is in a downward direction, indicating that electrical energy flows from the magnetosphere into the thermosphere, where it is converted into thermal and mechanical energy (i.e., through Joule heating). However, if the neutral flywheel effect occurs after the main phase of a geomagnetic storm, and the thermospheric dynamo dominates the magnetosphere-thermosphere coupling processes, then the net power will be in upward direction. In this case, the ionospheric dynamo transfers energy into the magnetosphere. Therefore, a detection of upward net power flux would provide more evidence of the flywheel effect.

Recently, Kelley et al. [1991] have used measurements from the HILAT satellite to determine the Poynting (power) flux in the high latitude thermosphere. They observed upward Poynting fluxes in some localized regions and suggested that the flywheel effect may provide such upward flux. Thayer and Vickrey [1992] studied this phenomenon further by comparing the available electrical energy flux stored in the neutral gas motion with that

\section{Potential}

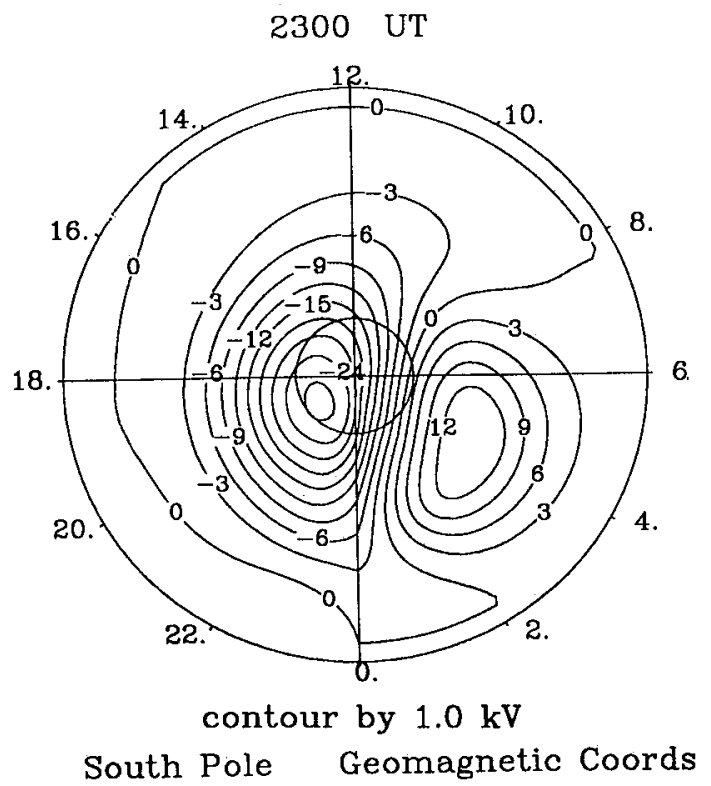

Fig. 6. The neutral driven potential calculated by assuming infinite magnetospheric load.

provided by the solar wind/magnetospheric dynamo. The net electrical flux was then obtained by adding the two fluxes together. This net electrical energy flux represents the maximum influence that ionospheric dynamo can have on high latitude electrodynamics and has a close relation with vertical Poynting flux [Thayer and Vickrey, 1992].

Figure $7 a$ shows the calculation of the net power flux distribution for $2200 \mathrm{UT}$, immediately before the end of the substorm, using a formula discussed by Thayer and Vickrey [1992]. The downward (positive) net electrical power flux is shown by open areas, while the upward (negative) net power flux is shown by hatched areas. As expected, the calculated storm-time net power flow is directed downward in the highlatitude thermosphere, and has a maximum that coincides with regions of dawn and dusk sunward convection (these are also the areas in which Joule heating is normally at its maximum), and with antisunward convection near local midnight. This downward flux indicates that the solar wind/magnetospheric dynamo dominates the electrodynamics of magnetospherethermosphere coupling, and that electrical energy from the magnetosphere is being converted to thermal energy (i.e., by Joule heating) and mechanical energy (through ion-neutral coupling) in the thermosphere. A small region of upward net power flux is seen in the dusk sector near the reversal areas of plasma convection, indicating that the neutral wind provides a electrical energy source in this region.

The distribution of the net power flux at $2300 \mathrm{UT}, 1$ hour after the end of main phase of the storm, is shown in Figure $7 b$. The net power flux flows upward in most regions of the high-latitude thermosphere at this time, with a strong maximum in the midnight sector and a weaker maximum in the dusk sector. This flux flows in the opposite direction to the storm time power flux, indicating that the thermospheric dynamo dominates globally in our simulation and that the electrical energy generated by the neutral wind circulation is transported upward to the magnetospheric load. However the total upward electrical 


\section{Power Flux}

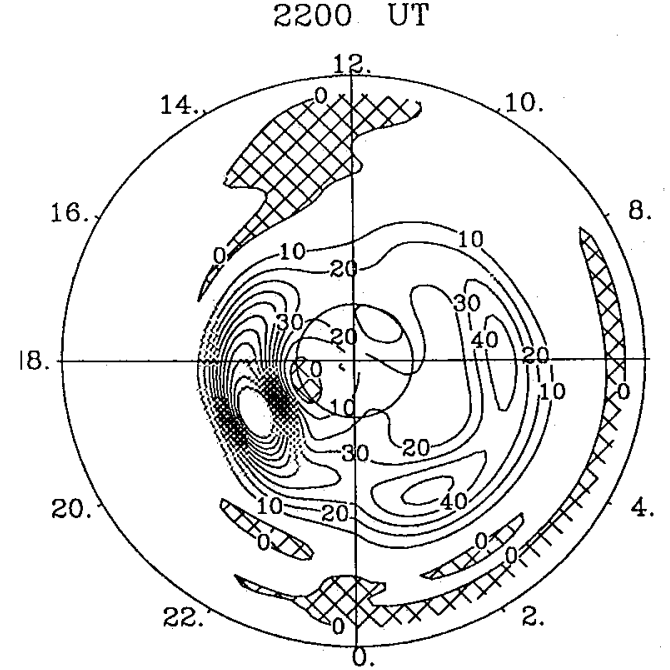

a) contour by $1.0 \mathrm{~mW} / \mathrm{m}^{2}$

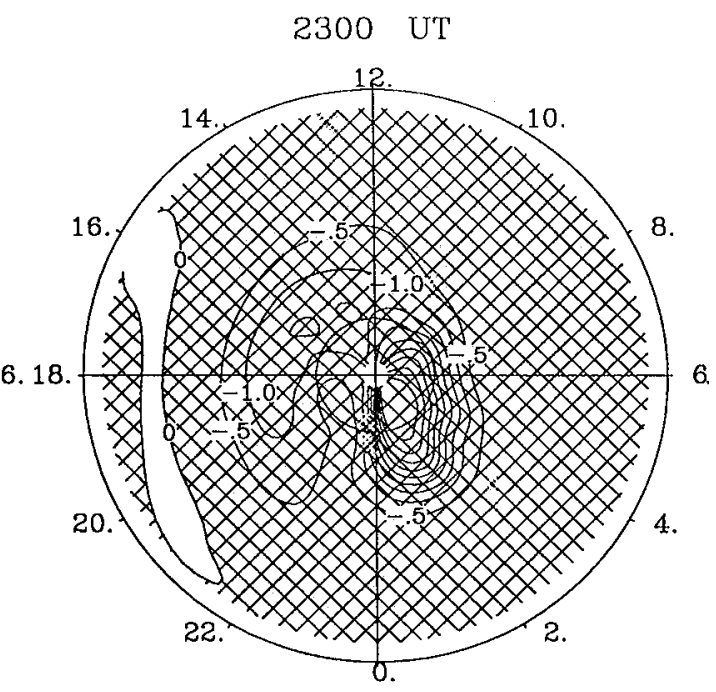

b) contour by $1.0 \mathrm{~mW} / \mathrm{m}^{2}$

$\square$ flux into ionosphere
flux away from ionosphere

\section{South Pole Geomagnetic Coords}

Fig. 7. The power flux calculated by assuming zero magnetospheric load both during the storm at (a) $2200 \mathrm{UT}$ and after the storm $(b)$ at $2300 \mathrm{UT}$.

energy over the polar cap (polarward of geomagnetic latitude $60^{0}$ ) at this time is only about $5 \%$ of the input to the thermosphere in the main phase of the storm at 2200 UT. This upward flux can be observed over the whole polar cap only if there is an almost complete shut down of the magnetospheric generator. Therefore, these effects are more likely to be detected only in local regions, such as the region of magnetospheric convection reversal where the magnetosphere imposed electrical field is close to zero.

\section{COMPARISON BETWEen DE 2 OBSERVATIONS AND MODEL RESULTS}

Although the November 23, 1982 geomagnetic storm provided a very good example of the flywheel effect for modeling purposes, insufficient data were available to provide experimental support for these theoretical studies. Therefore, we looked for another storm during which data that displayed flywheel effects existed. The small geomagnetic storm that occurred on December 7 and 8,1982 , provided such experimental support. Unlike the previous storm, there is no sharp cut-off in geomagnetic activity (Figure 8). Although $\mathrm{B}_{\mathrm{z}}$ turned northward at around 2000 UT, the magnitude of $B_{y}$ was greater than that of $B_{Z}$, a condition that usually results in the convection pattern continuing to have some characteristics associated with $\mathrm{B}_{\mathrm{z}}$ southward convection [McCormac et al., 1991]. Thus, to create a more accurate simulation of the data, we included some auroral forcing in the simulation for the period in which $B_{Z}$ was northward (until about 0100 UT on December 9). Two orbits of suitable data were available during this period. The first, orbit 7437 , occurred when $B_{Z}$ was still negative and has the characteristics of a fairly typical storm time circulation pattern. The other orbit, 7438 (which occurred when $B_{Z}$ was positive), has mixed characteristics, with some features indicating that the flywheel effect does in fact occur.

We have used simultaneous measurements from a number of the DE 2 instruments to calculate the local (as opposed to height-integrated) Hall and Pedersen currents, and the fieldaligned currents for two orbits during the main phase of the December 8 storm and in the period immediately following this main phase. The ion drift vectors needed for this calculation were obtained from the retarding potential analyzer (RPA) [Hanson et al., 1981] and the ion drift meter (IDM) [Heelis et al., 1981]. The neutral wind vectors were obtained from the Fabry-Perot interferometer (FPI) [Hays et al., 1981] and wind and temperature spectrometer (WATS) [Spencer et al., 1981]. The Langmuir probe [Krehbiel et al., 1981] gave electron temperatures and densities, while neutral temperatures and composition were determined by the WATS and the neutral atmospheric composition spectrometer (NACS) [Carignan et al., 1981], respectively. The magnetometer [Farthing et al., 1981] provided information about the magnetic field, which is used to calculate field-aligned currents. In this section we compare these experimental values of the Hall, Pedersen and field-aligned currents with similar local values that we calculated using an NCAR TIGCM simulation of the same storm.

Figures 9 and 10 show comparisons between model results and DE 2 data for orbit 7437 (see Figure 8 for its temporal position). During this orbit, and the other that will be discussed later, data were measured while the satellite was over the southern (summer) pole. The data from orbit 7437 show typical geomagnetic storm time behavior. $\mathrm{B}_{\mathrm{Z}}$ is southward, and the magnitudes of the neutral winds (Figure 9) are smaller than those of the ion winds, both over the polar cap and in the evening and 


\section{Cross-cap Potential}
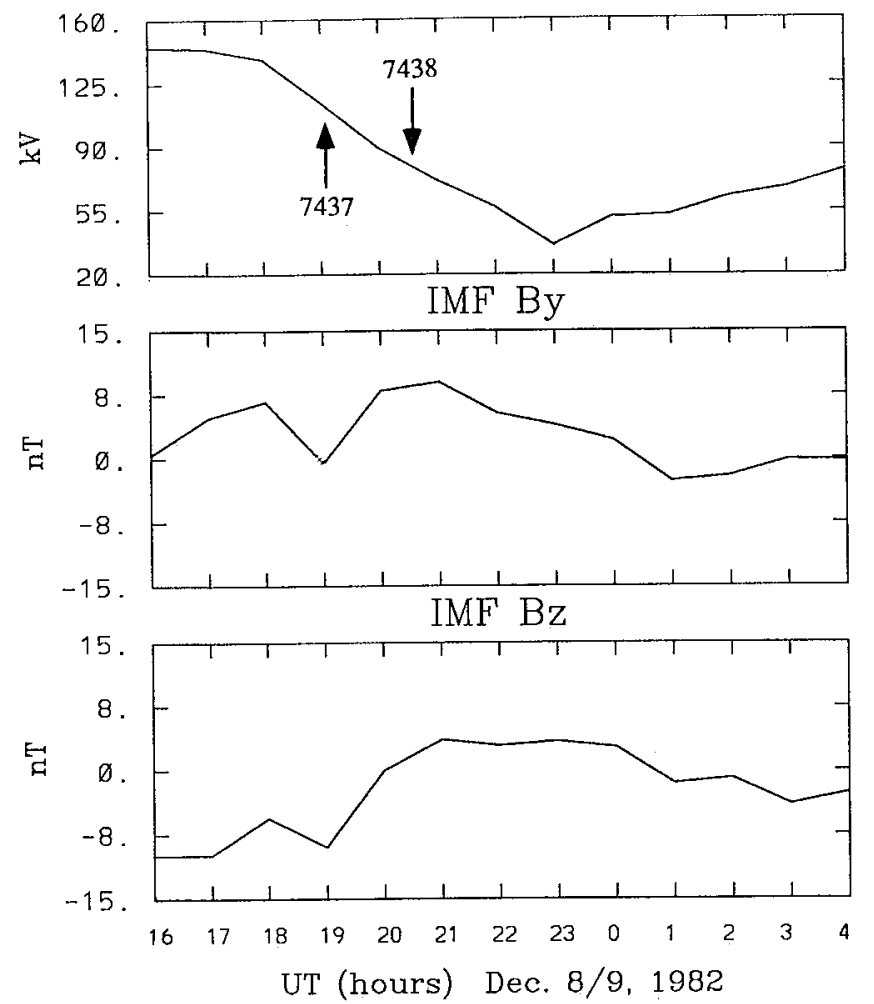

Fig. 8. Calculated cross-cap potential (Top) and measured IMF parameters during and following the main phase of the storm that occurred on December 8,1982 . The IMF values were made available by the National Space Science Data Center. (Middle) the IMF $B_{y}$ component. (Bottom) the $\mathrm{B}_{\mathrm{Z}}$ component. The UT for two DE 2 satellite passes is denoted by arrows.

morning auroral oval regions. Also, the direction of the neutral winds is similar to that of the ions. When model results are compared with data it can be seen that the neutral winds are similar in both magnitude and direction, except that there is no sunward flow in the morning sector of the model results. This difference is probably due either to varying geometries of the convection pattern, or to varying ion-neutral coupling time constants. The comparison between the modeled and observed ion winds is not as good; the auroral oval appears to be smaller in the modeled results and the "antisunward" winds in the polar cap are moving in a different direction, toward the evening sector rather than toward the dawn sector. As the modeled and observed neutral winds are in fairly good agreement, it is likely that these differences between the modeled and data-derived ion winds are the result of relatively shott-term changes in the ion convection pattern, which, because of their duration, could not be modeled successfully. These variations between the modeled and the data-derived ion winds result in velocity difference fields that are similar in the oval regions, but quite dissimilar over the polar cap.

Local Hall currents were also calculated from these velocity differences for orbit 7437 (Figure 10). Both the modeled currents and the data-derived currents behave in a way that is similar to the height-integrated Hall currents that were described by Figure 5 in Section 3. The ion winds dominate the Hall current system with strong currents flowing in an antisunward direction near the dawn and evening auroral oval, with weaker sunward currents being found over the polar cap. Generally, the modeled results and the data show fairly good agreement in both magnitude and direction in the auroral oval regions, but model amplitudes are somewhat larger over the polar cap. Additionally, the modeled Hall currents are directed toward dawn over the polar cap, while the data-derived currents are directed toward evening. This last difference occurs because the ion winds dominate the Hall currents over the polar cap at this time, and because the modeled ion winds blow in a different direction from the observed ion winds.

The Pedersen currents are also in fairly good agreement near the auroral oval, but the modeled and the data-derived Pedersen currents flow in opposite directions over the polar cap. Last, the agreement between the modeled field-aligned currents and the data is poor. The data-derived, field-aligned currents are calculated from the magnetometer data, whereas the modeled field-aligned currents are calculated from the divergence of the Pedersen current. Several factors that were discussed earlier probably contribute to the smaller modeled field-aligned currents. First, the resolution of the NCAR TIGCM is $5^{\circ}$ by $5^{\circ}$, while the width of the field-aligned current features is of the order of about $5^{\circ}$. Therefore, the TIGCM will not resolve adequately the changes in ion and neutral velocity that give rise to field-aligned currents. Second, applying the VSH algorithm entails further smoothing of these data. As regions of negative (downward) field-aligned currents are immediately adjacent to positive field-aligned currents, these two smoothing processes act both to decrease the magnitude of the field-aligned currents and to increase the widths of the region 1 and 2 currents. Third, the calculated auroral oval (at least in as much as it applies to the ion winds) is smaller than the observed auroral oval, so the field-aligned currents on the evening side of the auroral oval are displaced polarward relative to the observed field-aligned currents. Fourth, even if the auroral oval is properly described, it is unlikely that field-aligned currents could be modeled, especially as we have no knowledge of the magnetospheric load. Overall, it appears that a more accurate calculation of fieldaligned currents using the divergence of the Pedersen currents in $\mathrm{a}_{\mathrm{Z}}$ southward case would require a model with higher resolution, and a better knowledge of the appropriate auroral prescriptions.

About the time that orbit 7438 occurred, $\mathrm{B}_{\mathrm{Z}}$ turned northward. In this case, $B_{z}$ was weaker than $B_{y}$ and the ion winds still behaved in a manner that was appropriate for $B_{Z}$ southward conditions but they moved with significantly reduced speed. Despite this $\mathrm{B}_{\mathrm{Z}}$ southward type of ion convection pattern during orbit 7438 , the neutrals had been accelerated by the stronger ion winds that had existed earlier. Consequently, the antisunward neutral winds across the polar cap blow more strongly than the antisunward ion winds and the velocity difference becomes close to the direction of neutral winds in most of the polar cap (Figure 11). A local flywheel effect exists. Modeled neutral winds are again in reasonable agreement with those observed from the $D E$ 2 satellite. The magnitudes and direction are much the same, except on the dawn side of the auroral oval, where a reversal to sunward flow is seen in the DE 2 winds, but not in the modeled neutral winds. The modeled ion winds are also very similar to the observed ion winds, although these modeled winds around the auroral oval (the regions of sunward winds) are a little weaker than the observed ion winds. As the modeled and the observed neutral and ion winds are very similar, the difference winds are also similar.

Figure 12 displays the observed and modeled currents for orbit 


\section{$\mathrm{DE}-2$ vs TIGCM}
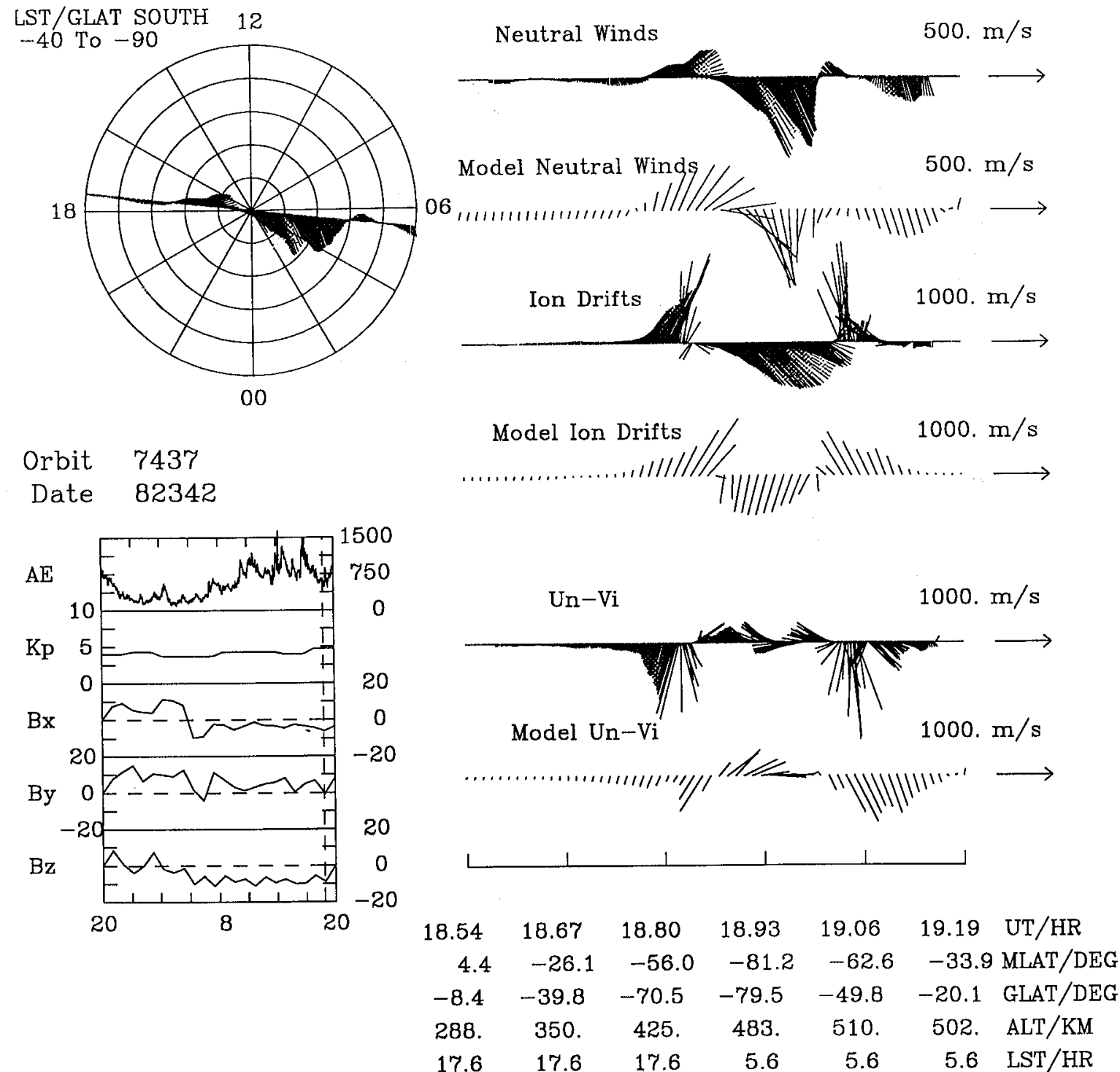

Fig. 9. A summary of observed and derived ionosphere-thenmosphere conditions plotted along the track of the Dynamics Explorer 2 satellite during orbit 7437 . The observed and modeled neutral winds are shown in the top two traces, which are plotted against time, geomagnetic latitude, geographic latitude, local time and the spacecraft altitude as it passes over the southern (summer) hemisphere. The third and fourth traces show observed and modeled ion winds, while traces 5 and 6 show the velocity differences. The sunward direction is upward. The bottom inset to the left shows the time history of the IMF components and geophysical indices $A E$ and $K p$ for 24 hours prior to the orbit pass. The midpoint UT for this satellite pass is denoted by the vertical dotted line on this IMF plot. The top inset to the left shows a polar dial (geographic latitude and solar local time) for the pass, with the neutral winds plotted.

7438. Neutral winds are stronger than ion winds over much of the polar cap. This causes antisunward local Hall currents over the polar cap: a local flywheel effect takes place. On the whole, the model overpredicts the magnitudes of the Hall currents, and, as the modeled and observed ion-neutral velocity differences are similar, this suggests that the local Hall conductivity is also overpredicted, probably as a result of overly large neutral densities. Agreement between the modeled and observed Pedersen and field-aligned currents is poor. The field-aligned currents still display region 1 and region 2 type of behavior, but both the modeled and the observed currents are weaker than they were during the previous orbit. As these field-aligned currents still show region 1 and region 2 type of behavior, the reasons why their magnitudes are not modeled accurately are probably the same as those outlined earlier.

Overall, these two orbits provide some indication of the existence of a "local" (as opposed to height-integrated) flywheel effect in the $F$ region in the period immediately following the main phase of a geomagnetic storm. Our modeling efforts reproduce this "local" effect very well, giving us some confidence in the results of our earlier modeling, where we found that a height-integrated flywheel effect exists that persists for several hours after the end of the main phase of a geomagnetic storm. The field-aligned current modeling was not as successful, although region 1 and 2 currents were reproduced during $B_{Z}$ southward conditions. Not only were there problems 


\section{DE - 2 vs TIGCM}
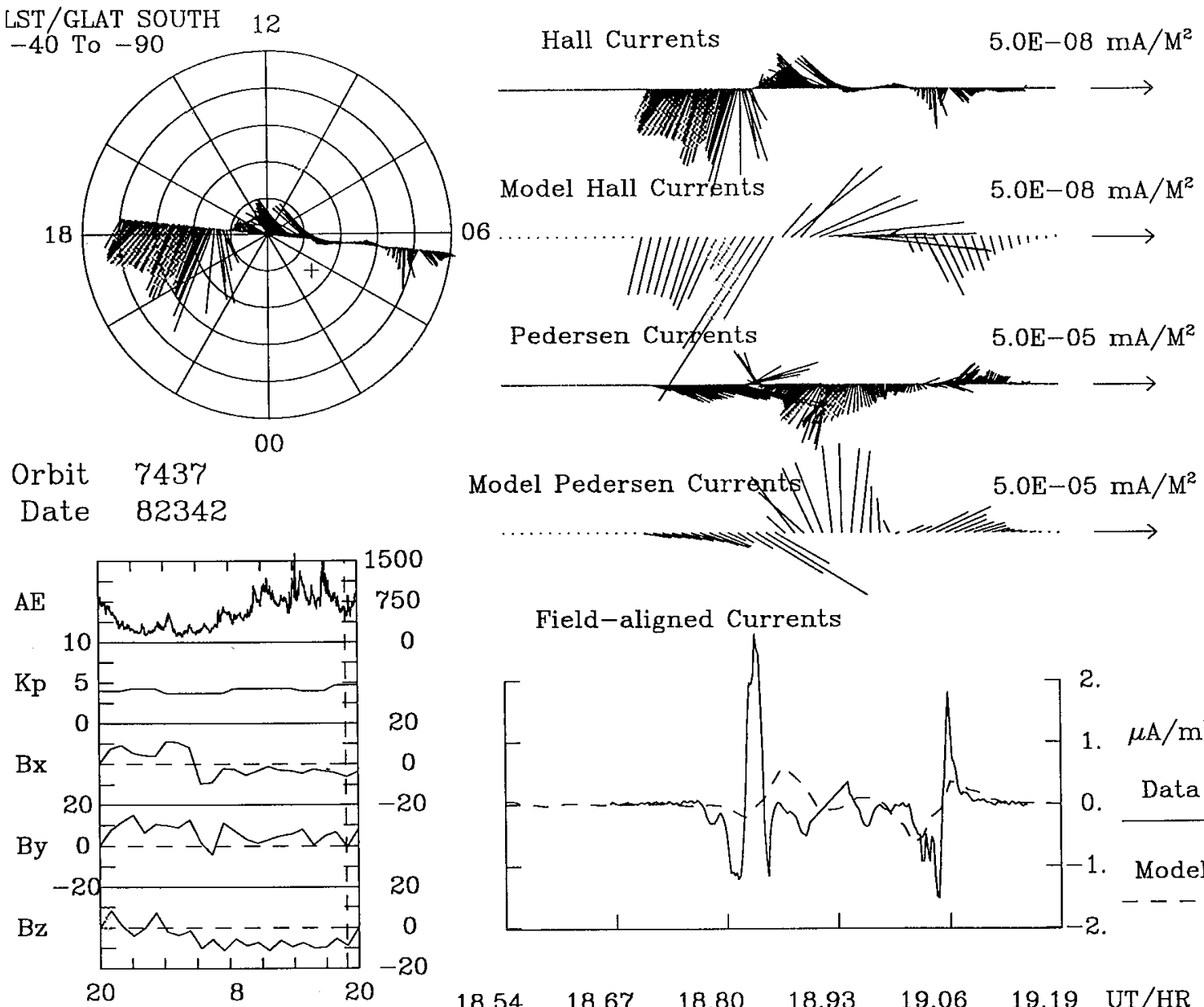

Field-aligned Currents

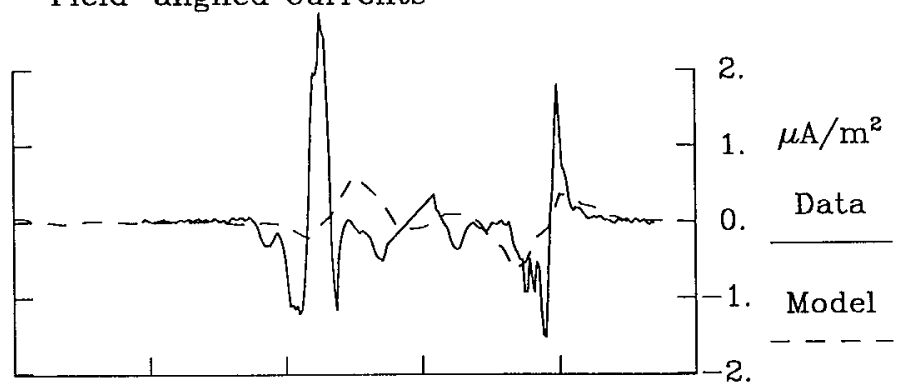

$\begin{array}{ccccccc}18.54 & 18.67 & 18.80 & 18.93 & 19.06 & 19.19 & \mathrm{UT} / \mathrm{HR} \\ 4.4 & -26.1 & -56.0 & -81.2 & -62.6 & -33.9 \mathrm{MLAT} / \mathrm{DEG} \\ -8.4 & -39.8 & -70.5 & -79.5 & -49.8 & -20.1 & \mathrm{GLAT} / \mathrm{DEG} \\ 288 . & 350 . & 425 . & 483 . & 510 . & 502 . & \mathrm{ALT} / \mathrm{KM} \\ 17.6 & 17.6 & 17.6 & 5.6 & 5.6 & 5.6 & \mathrm{LST} / \mathrm{HR}\end{array}$

Fig. 10. A graph of the observed and modeled Hall currents (traces 1 and 2), Pedersen currents (traces 3 and 4) and fieldaligned currents (trace 5) for orbit 7437. These currents are normalized to the values at $400 \mathrm{~km}$ using the scale height of their conductivities. The sunward direction is upward. The bottom inset to the left shows the time history of the IMF components and geophysical indices $A E$ and $K p$ for 24 hours prior to the orbit pass. The midpoint UT for this satellite pass is denoted by the vertical dotted line on this IMF plot. The top inset to the left shows a polar dial (geographic latitude and solar local time) for the pass, with the Hall currents plotted. The plus sign in this inset indicates the position of the geomagnetic pole.

with model resolution and auroral prescriptions in this case, but also there was no information available about the probable magnetospheric load.

\section{SUMMARY}

We have conducted an investigation into neutral flywheel effects using NCAR-TIGCM simulation of geomagnetic storms that occurred on November 23, 1982, and December 7-8, 1982. Theoretical calculations from the latter storm have been compared with the measurements of currents from instruments on the Dynamics Explorer 2 satellite. The principal conclusions of the study are as follows:

1. Neutral flywheel effects can make a contribution to high latitude electrodynamics for a few hours after the main phase of geomagnetic storm. These effects have the potential to return about $5 \%$ of the storm-time input of electrical energy to the magnetosphere.
2. The Hall currents that are driven by neutral winds during $B_{Z}$ northward conditions are generally in the opposite direction to those that occur during $B_{Z}$ southward conditions, when they are driven primarily by ion winds. These neutral-wind-driven Hall currents may contribute as much as $80 \%$ of the polar Hall current system early in the recovery period. Such transient effects may last several hours.

3. The morphology of the field-aligned current system calculated by the NCAR-TIGCM during southward $\mathrm{B}_{\mathrm{Z}}$ conditions is in general agreement with observations, except for smearing effects due to the limited $\left(5^{\circ} \times 5^{\circ}\right)$ spatial resolution of the model. Field-aligned currents, driven by neutral winds, may make a contribution to the total field-aligned current system during northward $\mathrm{B}_{\mathrm{Z}}$ conditions, but the magnitudes of these currents appear to be too small to account for the majority of the fieldaligned current system.

4. DE 2 measurements have provided supporting evidence for 


\section{DE-2 vs TIGCM}

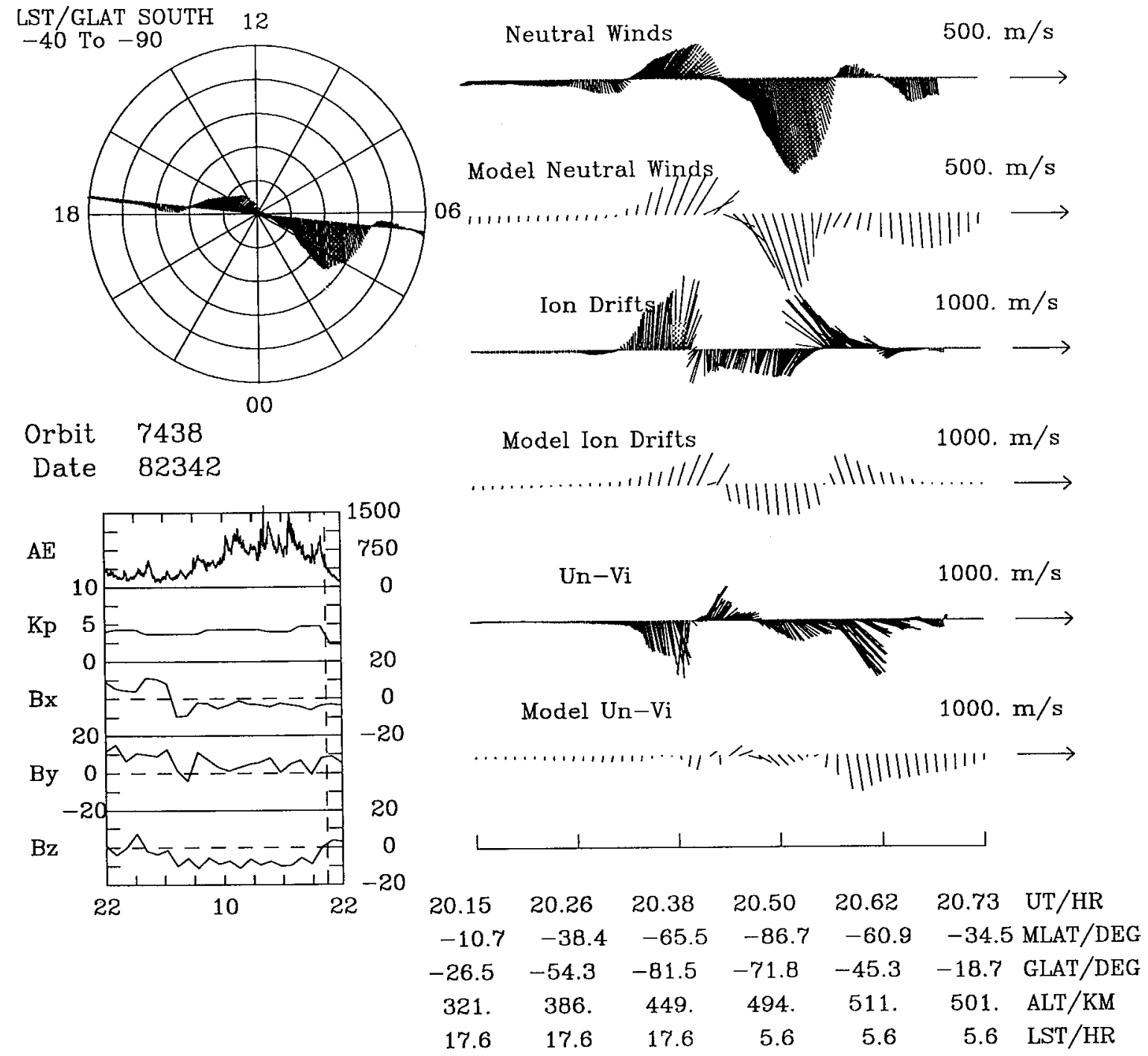

Fig. 11. The same as Figure 9, except for orbit 7438.

the existence of the flywheel effect by showing that "local" flywheel effects can occur at satellite altitudes. These observed "local" flywheel effects are in reasonable agreement with modeled "local" Hall currents, giving confidence that the modeled, height-integrated flywheel effect may happen.

5. Most of the areas of disagreement between model predictions of Hall currents and those derived from DE 2 data can be explained by our use of a not-fully-realistic ion convection pattern and overestimation of neutral densities in the model.

6. Detailed comparisons between modeled field-aligned currents and DE-2 measurements indicate that the predicted fieldaligned current distribution may provide smoothed, average values for the large scale features, but cannot resolve the observed spatial distribution and amplitude at the current model resolution.

7. In the period following the main phase of a geomagnetic storm, large neutral-dynamo-driven polarization electric fields of $20-30 \mathrm{kV}$ are calculated if the magnetosphere is assumed to be characterized by an infinite electrical load

\section{APPENDIX}

At high latitudes a horizontal electric field near the poles can drive horizontal Pedersen and Hall currents which flow in the direction of $\mathbf{E}$ and $\mathbf{B} \times \mathbf{E}$, respectively, such that [Brekke et al., 1974]

$$
\mathbf{J}_{\perp}=\sigma_{\mathrm{P}} \mathbf{E}^{\prime}+\sigma_{\mathrm{H}} \mathbf{B} \times \mathbf{E}^{\prime}
$$

where $\mathbf{E}^{*}(=\mathbf{E}+\mathbf{U} \times \mathbf{B})$ is the effective electric field consisting of the electrostatic field $\mathbf{E}$ and the neutral wind term $\mathbf{U} \times \mathbf{B}$. The $\sigma_{\mathrm{p}}$ and $\sigma_{\mathrm{H}}$ are the Pedersen and Hall conductivities respectively. In the upper ionosphere the electric field is related to plasma convection $\mathbf{V}_{\mathbf{i}}$ through

$$
\mathbf{E}=-\mathbf{V}_{\mathbf{i}} \times \mathbf{B}
$$

This electric field can be mapped down along the magnetic field lines into the $\mathrm{E}$ region by assuming that there is no potential drop along the magnetic field lines. Even though the potential drop along a field line may not be negligible within the ionosphere, it should be small compared to the potential variations transverse to the magnetic field, so this assumption 


\section{DE-2 vs TIGCM}
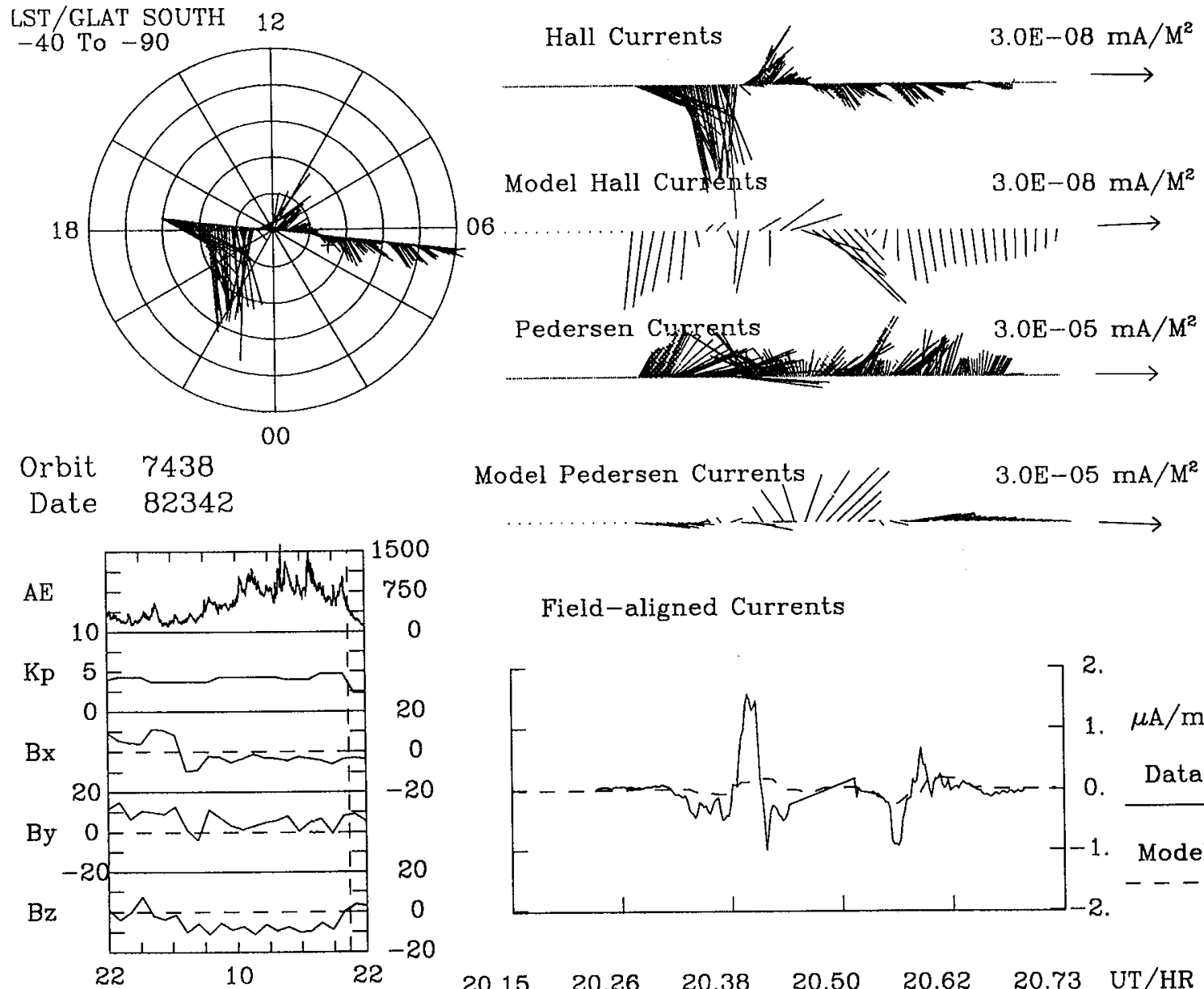

Field-aligned Currents

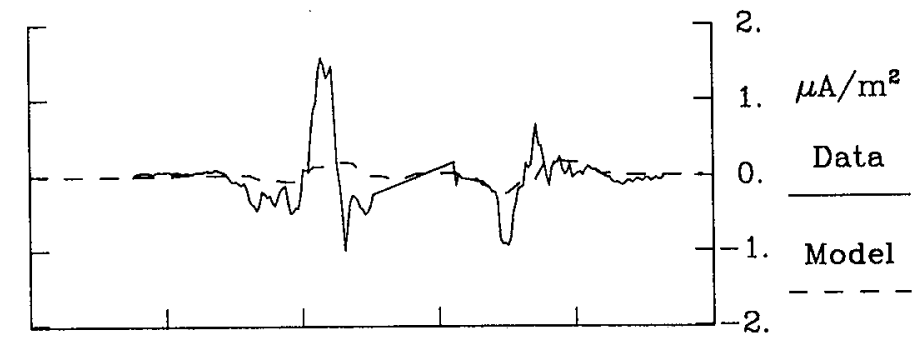

$\begin{array}{ccccccc}20.15 & 20.26 & 20.38 & 20.50 & 20.62 & 20.73 & \text { UT/HR } \\ -10.7 & -38.4 & -65.5 & -86.7 & -60.9 & -34.5 & \text { MLAT/DEG } \\ -26.5 & -54.3 & -81.5 & -71.8 & -45.3 & -18.7 & \text { GLAT/DEG } \\ 321 . & 386 . & 449 . & 494 . & 511 . & 501 . & \text { ALT/KM } \\ 17.6 & 17.6 & 17.6 & 5.6 & 5.6 & 5.6 & \text { LST } / \mathrm{HR}\end{array}$

Fig. 12. The same as Figure 10, except for orbit 7438.

is valid. With this assumption, the F region electric field can be mapped down to the $E$ region without changing either magnitude or direction. Therefore, equation (A2) is also valid in the $\mathrm{E}$ region, given that $V_{\mathbf{i}}$ represents the ionospheric response to the external field in the $\mathrm{F}$ region. The height-integrated Hall currents are given by

$$
\mathbf{J}_{H}=\int_{z_{0}}^{+\infty} \sigma_{H} B U d z-B \Sigma_{H} \mathbf{V}_{i}
$$

where $\mathrm{z}_{0}$ is the altitude of bottom ionosphere, $\Sigma_{\mathrm{H}}$ is the heightintegrated Hall conductivity, $\mathbf{U}$ and $\mathbf{V}_{\mathbf{i}}$ are the components of neutral and ion velocities perpendicular to the magnetic field and $B$ is the magnitude of the Earth's magnetic field. Under the assumption of a perfectly conducting magnetosphere, the neutral dynamo acts as a pure current generator which drives the neutral component of Hall current $\left(\mathbf{J}_{\mathbf{n}}\right)$, the first term on the right-hand side of equation (A3). The second term on the right hand side, which has a negative sign, is defined as the ion component $\left(\mathbf{J}_{\mathbf{i}}\right)$ which represents the current driven by the magnetospheric electric field. In general, the ion drift component is much larger than the neutral wind component when $B_{Z}$ is southward. Thus, the Hall current system is driven primarily by ion winds and is slightly damped by neutral winds. More interestingly when the ion winds decrease in magnitude or change direction the neutral winds can drive Hall currents in directions that are opposite to the ion-driven Hall currents.

The neutral winds also drive Pedersen currents that have a nonzero divergence. Under the assumption of zero magnetospheric load this divergence is assumed to be continually balanced by field-aligned currents, and there is no significant modification of the ionospheric electric field. If the gradient in height-integrated Hall conductivity is ignored, the field-aligned current is given by

$$
\mathrm{J}_{\|}=-\nabla \cdot \mathrm{JP}_{\mathbf{P}}
$$

where $J_{\|}$is positive in the upward direction and $J_{\mathbf{P}}$ is the height-integrated Pedersen current. In order to calculate the 
divergence accurately, we used a VSH technique [Killeen et al., 1987], in which the horizontal current $\mathbf{J}_{\perp}$ is expressed as the sum of the irrotational potential function $\xi$ and the nondivergent stream function $\psi$ :

$$
\mathbf{J}_{\perp}(\theta, \lambda)=\nabla \xi(\theta, \lambda)+\nabla \times \mathbf{k} \psi(\theta, \lambda)
$$

where $\mathbf{k}$ is the unit vector from the center of the Earth. The potential function $\xi$ and the stream function $\psi$ are calculated by performing a spectral expansion in latitude and longitude of the currents using the VSH algorithm. Once the potential function is available, field-aligned currents can be calculated easily with

$$
\mathrm{J}_{\|}=-\nabla^{2} \xi_{\mathrm{p}}
$$

where $\xi_{\mathrm{p}}$ is the potential function of the Pedersen current obtained by factoring (A5) into Hall and Pedersen components.

Acknowledgments This study was supported by NASA grants NAGW1535 and NAG5-465, by NSF grant ATM-8918476 and by USAF grant F19628-89-K-0026 to the University of Michigan. The authors are grateful to W. B. Hanson, R. A. Heelis, G. R. Carignan, L. H. Brace and $\mathrm{N}$. W. Spencer for providing their DE 2 data. Useful discussions were also held with R. A. Heelis, P. Reiff, B. A. Emery and J. P. Thayer. We also wish to acknowledge the National Center for Atmospheric Research, sponsored by NSF, for the computing time used in this research.

The Editor thanks T. A. Potemra and J. J. Sojka for their assistance in evaluating this paper.

\section{REFERENCES}

Blanc M. and A. D. Richmond, The ionospheric disturbance dynamo, $J$. Geophys. Res., 85, 1669-1686, 1980.

Brekke, A., J. R. Doupnik and P. M. Banks, Incoherent scatter measurements of $\mathrm{E}$ region conductivities and currents in the auroral zone, J. Geophys. Res., 79, 3773-3790, 1974.

Burke, W. J., M. C. Kelley, R. C. Sagalyn, M. Smiddy and S. T. Lai, Polar cap electric field structures with a northward interplanetary magnetic field, Geophys. Res. Lett., 6, 21-24, 1979.

Burns, A. G., T. L. Killeen and R. G. Roble, Thermospheric composition changes seen during a geomagnetic storm, Adv. Space Res., 12 (10), 253-256, 1992.

Carignan, G. R., B. P. Block, J. C. Maurer, A. E. Hedin, C. A. Reber and N. W. Spencer, The neutral mass spectrometer on Dynamics Explorer, Space Sci. Instrum., 5, 429-441, 1981.

Deng, W., T. L. Killeen, A. G. Burns and R. G. Roble, The flywheel effect: ionospheric currents after a geomagnetic storm, Geophys. Res. Lett., 18, 1845-1848, 1991.

Dickinson, R. E., E. C. Ridley, and R. G. Roble, A three-dimensional, timedependent general circulation model of the thermosphere, J. Geophys. Res., 86, 1499-1512, 1981.

Dickinson, R. E., E. C. Ridley and R. G. Roble, Thermospheric general circulation with coupled dynamics and composition, J. Atmos. Sci., 41, 205-219, 1984.

Farthing, W. H., M. Sugiura, B. G. Ledley and L. J. Cahill, Jr., Magnetic field observations on DE-A and -B, Space Sci. Instrum., 5, 551-560, 1981.

Forbes, J. M. and M. Harel, magnetosphere-thermosphere coupling: An experiment in interactive modeling, $J$. Geophys. Res., 94, 2631-2644, 1989.

Forbes, J. M. and R. S. Lindzen, Atmospheric solar tides and their electrodynamic effects, I, The global Sq current system, J. Atmos. Terr. Phys., 38, 897-910, 1976a.

Forbes, J. M. and R. S. Lindzen, Atmospheric solar tides and their electrodynamic effects, II, The equatorial electrojet. J. Atmos. Terr. Phys., 38, 911, 1976 b.

Forbes, J. M. and R. S. Lindzen, Atmospheric solar tides and their electrodynamic effects, III, The polarization electric field, J. Atmos. Terr. Phys., 39, 1369-1377, 1977.
Hanson, W. B., R. A. Heelis, R. A. Power, C. R. Lippincott, D. R. Zuccaro, B. J. Holt, L. H. Harmon, and S. Sanatani, The retarding potential analyzer for Dynamics Explorer-B, Space Sci. Instrum., 5, 503-510, 1981 .

Hays, P. B., J. W. Meriwether and R. G. Roble, Nighttime thermospheric winds at high latitudes, J. Geophys. Res., 84, 1905-1913, 1979.

Hays, P. B., T. L. Killeen, and B. C. Kennedy, The Fabry-Perot interferometer on Dynamics Explorer, Space Sci. Instrum., 5, 395-416, 1981 .

Hays, P. B., T. L. Killeen, N. W. Spencer, L. E. Wharton, R. G. Roble, B. E. Emery, T. J. Fuller-Rowell, D. Rees, L. A. Frank, and J. D. Craven, Observations of the dynamics of the polar thermosphere, J. Geophys. Res., 89, 5597-5612, 1984.

Heelis, R. A., W. B. Hanson, C. R. Lippincott, D. R. Zuccaro, L. H. Harmon, B. J. Holt, J. E. Doherty, and R. A. Power, The ion drift meter for Dynamics Explorer -B, Space Sci. Instrum., 5, 511-521, 1981.

Heelis, R. A., J. K. Lowell, and R. W. Spiro, A model of the high-latitude ionospheric convection pattern, J. Geophys. Res., 87, 6339-6345, 1982.

Heppner, J.P., Empirical models of high-latitude electric fields, $J$. Geophys. Res., 82, 1115-1125, 1977.

lijima, T., and T. A. Potemra, Large-scale characteristics of field-aligned currents associated with substorms, J. Geophys. Res., 83, 599-615, 1978.

lijima, T., T. A. Potemra, L. J. Zanetti and P. F. Bythrow, Large-scale Birkeland currents in the dayside polar region during strongly northward IMF: A new Birkeland current system, J. Geophys Res., 89 7441-7452, 1984.

Kelley, M. C., D. J. Knudsen and J. F. Vickery, Poynting flux measurements on a satellite: A diagnostic tool for space research, $J$. Geophys. Res., 96, 201-207, 1991.

Killeen, T. L., and R. G. Roble, An analysis of the high-latitude thermospheric wind pattem calculated by a thermospheric general circulation model, 1, Momentum forcing, J. Geophys. Res., 89, 7509$7522,1984$.

Killeen, T. L., P. B. Hays, N. W. Spencer, and L. E. Wharton, Neutral winds in the polar thermosphere as measured from Dynamics Explorer, Geophys. Res. Lett., 9, 957-960, 1982.

Killeen, T. L., P. B. Hays, G. R. Carignan, R. A. Heelis, W. B. Hanson, N. W. Spencer, and L. H. Brace, Ion-neutral coupling in the high latitude F region: Evaluation of ion heating terms from Dynamics Explorer 2, $J$. Geophys. Res., 89, 7495-7508, $1984 a$.

Killeen, T. L., R. W. Smith, P. B. Hays, N. W. Spencer, L. E. Wharton, and F. G. McCormac, Neutral winds in the high-latitude winter $F$ region: Coordinated observations from ground and space, Geophys. Res. Lett., 11, 311-314, $1984 b$.

Killeen, T. L., R. W. Smith, N. W. Spencer, J. W. Meriwether, D. Rees, G. Hernandez, P. B. Hays, L. L. Cogger, D. P. Sipler, M. A. Biondi and C. A. Tepley, Mean neutral circulation in the winter polar $\mathrm{F}$ region, $J$. Geophys. Res., 91, 1633-1649, 1986.

Killeen, T. L., R. G. Roble and N. W. Spencer, A computer model of global thermospheric wind and temperatures, Adv. Space Res., 7, 207$215,1987$.

Krehbiel, J. P., L. H. Brace, R. F. Theis, W. H. Pinkus, and R. B. Kaplan, The Dynamics Explorer Langmuir probe instrument, Space Sci. Instrum., 5, 493-502, 1981.

Lyons, L. R., T. L. Killeen, and R. L. Walterscheid, The neutral "flywheel" as a source of quiet-time, polar cap currents, Geophys. Res. Lett., 12, 101-104, 1985.

Maezawa, K., Magnetospheric convection induced by the positive and negative $\mathrm{Z}$ components of the interplanetary magnetic field: Quantitative analysis using polar cap magnetic records, J. Geophys. Res., 81, 2289-2303, 1976

McCormac, F. G., T. L. Killeen and J. P. Thayer, The influence of IMF By on the high-latitude thermospheric circulation during northward IMF, $J$. Geophys. Res., 96, 115-128, 1991.

Ponthieu, J.-J., T. L. Killeen, K.-M. Lee, G. R. Carignan, W. R. Hoegy, and L. H. Brace, Ionosphere-thermosphere momentum coupling at solar maximum and solar minimum from $\mathrm{DE}-2$ and $\mathrm{AE}-\mathrm{C}$ data, Physica Scripta, 37, 447-454, 1988.

Reiff, P. H., Sunward convection in both polar caps, J. Geophys. Res., 87, 5976-5980, 1982.

Reiff, P. H. and J. G. Luhmann, Solar wind control of the polar-cap voltage, in Solar Wind-Magnetosphere Coupling, edited by Y. Kamide and J. A. Slavin, pp453-476, Terra Scientific Publishing Company, 
Tokyo, Japan, 1986

Reiff, P. H., R. W. Spiro, R. A. Wolf, Y. Kamide and J. H. King, Comparison of polar cap potential drops estimated from solar wind and ground magnetometer data: CDAW 6, J. Geophys. Res., 90, 1318-1324, 1985.

Richmond, A. D. and Y. Kamide, Mapping electrodynamic features of the high-latitude ionosphere from localized observations: Technique, $J$. Geophys. Res., 93, 5741-5759, 1988.

Richmond, A. D. and R. G. Roble, Electrodynamic effects of thermospheric winds from the NCAR thermospheric general circulation model, J. Geophys. Res., 92, 12,365-12,376, 1987.

Roble, R. G., R. E. Dickinson, and E. C. Ridley, Global circulation and temperature structure of the thermosphere with high-latitude plasma convection, J. Geophys. Res., 87, 1599-1614, 1982.

Roble, R. G., B. A. Emery, R. E. Dickinson, E. C. Ridley, T. L. Killeen, P. B. Hays, G. R. Carignan, and N. W. Spencer, Thermospheric circulation, temperature and compositional structure of the southern hemisphere polar cap during October-November, 1981, J. Geophys. Res., 89, 9057-9068, 1984.

Roble, R. G., E. C. Ridley, A. D. Richmond and R. E. Dickinson, A coupled thermosphere/ionosphere general circulation model, Geophys. Res. Lett., 15, 1325-1328, 1988.

Sojka, J. J., and R. W. Schunk, Problems with deducing ionospheric plasma convection patterns, J. Geophys. Res., 91, 259-269, 1986.
Spencer, N. W., L. E. Wharton, H. B. Niemann, A. E. Hedin, G. R. Carignan, and J. C. Maurer, The Dynamics Explorer wind and temperature spectrometer, Space Sci. Instrum. 5, 417-428, 1981.

Thayer, J. P. and J. F. Vickrey, On the contribution of thermospheric neutral wind to high-latitude Energetics, Geophys. Res. Lett., 19, 265268,1992

Zanetti, L. J., T. A. Potemra, T. Iijima, W. Baumjohann, and P. F. Bythrow, lonospheric and Birkeland current distributions for northward interplanetary magnetic field: Inferred polar convection, $J$. Geophys, Res., 89, 7453-7458, 1984.

A. G. Burns, W. Deng, T. L. Killeen, Space Physics Research Laboratory, Department of Atmospheric, Oceanic and Space Sciences, The University of Michigan, Ann Arbor, Michigan 48109-2143.

R. G. Roble, High Altitude Observatory, National Center for Atmospheric Research, Boulder, Colorado 80303.

J. Slavin, NASA Code 696, Goddard Space Flight Center, Greenbelt, Maryland 20771

L. E. Wharton, NASA Code 614, Goddard Space Flight Center, Greenbelt, Maryland 20771

(Received March 16, 1992;

revised September 14, 1992;

accepted September 15, 1992.) 